\title{
TimeSpec4LULC: A Global Deep Learning-driven Dataset of MODIS Terra-Aqua Multi-Spectral Time Series for LULC Mapping and Change Detection
}

\author{
Rohaifa Khaldi ${ }^{1}$, Domingo Alcaraz-Segura ${ }^{1,3}$, Emilio Guirado ${ }^{4}$, Yassir Benhammou ${ }^{5}$, Abdellatif El \\ Afia $^{2}$, Francisco Herrera ${ }^{5}$, and Siham Tabik ${ }^{5}$ \\ ${ }^{1}$ Dept. of Botany, Faculty of Science, University of Granada, 18071 Granada, Spain \\ ${ }^{2}$ ENSIAS, Mohammed V University, Rabat, 10170, Morocco \\ ${ }^{3}$ iEcolab, Inter-University Institute for Earth System Research, University of Granada, 18006 Granada, Spain \\ ${ }^{4}$ Multidisciplinary Institute for Environment Studies "Ramón Margalef", University of Alicante, 03690, Spain \\ ${ }^{5}$ Dept. of Computer Science and Artificial Intelligence, Andalusian Research Institute in Data Science and Computational \\ Intelligence, DaSCI, University of Granada, 18071, Granada, Spain
}

Correspondence: Rohaifa Khaldi (rohaifa@ugr.es); Domingo Alcaraz-Segura (dalcaraz@ugr.es)

\begin{abstract}
Land Use and Land Cover (LULCs) mapping and change detection are of paramount importance to understand the distribution and effectively monitor the dynamics of the Earth's system. An unexplored way to create global LULC maps is by building good quality LULC-models based on state-of-the-art deep learning networks. Building such models requires large global good quality time series LULC datasets, which are not available yet. This paper presents TimeSpec4LULC (Khaldi

5 et al., 2021), a smart open-source global dataset of multi-Spectral Time series for 29 LULC classes. TimeSpec4LULC was built based on the 7 spectral bands of MODIS sensor at $500 \mathrm{~m}$ resolution from 2002 to 2021, and was annotated using a spatial agreement across the 15 global LULC products available in Google Earth Engine. The 19-year monthly time series of the seven bands were created globally by: (1) applying different spatio-temporal quality assessment filters on MODIS Terra and Aqua satellites, (2) aggregating their original 8-day temporal granularity into monthly composites, (3) merging their data into

10 a Terra+Aqua combined time series, and (4) extracting, at the pixel level, 11.85 million time series for the 7 bands along with a set of metadata about geographic coordinates, country and departmental divisions, spatio-temporal consistency across LULC products, temporal data availability, and the global human modification index. To assess the annotation quality of the dataset, a sample of 100 pixels, evenly distributed around the world, from each LULC class, was selected and validated by experts using very high resolution images from both Google Earth and Bing Maps imagery. This smartly, pre-processed, and annotated dataset is targeted towards scientific users interested in developing and evaluating various machine learning models, including deep learning networks, to perform global LULC mapping and change detection.
\end{abstract}


https://doi.org/10.5194/essd-2021-253

Preprint. Discussion started: 12 October 2021

(c) Author(s) 2021. CC BY 4.0 License.

(c) (i)

\section{Introduction}

Accurate Land-Use and Land-Cover (LULC) information, including distribution, dynamics and changes, is of paramount importance for understanding and modelling the natural and human-modified behavior of the Earth's system (Tuanmu and Jetz, 2014; Verburg et al., 2009). Land cover is an essential variable that provides powerful insights for the assessment and modelling of terrestrial ecosystem processes, biogeochemical cycles, biodiversity, climate, and water resources, etc. (Luoto et al., 2007; Menke et al., 2009; Polykretis et al., 2020). Land uses incorporate many types of modifications that an increasing human population, 9 billion expected by 2050, causes to the Earth surface. LULCs are subjected to anomalies, trends and changes both from anthropogenic and natural origins (Polykretis et al., 2020), with subsequent modifications on their biophysical properties. LULC change is usually interpreted as the conversion from one LULC category to another or/and the modification of land management within LULC (Meyer et al., 1994). The assessment of LULC and LULC change has been identified as an essential planetary boundary to assess the status and trends of social-ecological systems from the local to the global scale in the pursuit of a safe operating space for humanity. For instance, urban sprawl and agriculture expansion or abandonment affect the biodiversity, soil quality, climate, food security, and human health (Lambin and Geist, 2008; Feddema et al., 2005). For this reason, continuous and accurate LULC and LULC change mapping is essential in policy and research to monitor ecological and environmental change at different temporal and spatial scales (Polykretis et al., 2020; García-Mora et al., 2012), and as a decision support system to ensure an effective and sustainable planning and management of natural resources (Kong et al., 2016; Congalton et al., 2014; Grekousis et al., 2015).

Satellite remote sensing in combination with geographic information systems (GIS) have provided convenient, inexpensive, and continuous spatio-temporal information for mapping LULCs and detecting changes on the Earth's surface from regional to global scales (Kong et al., 2016; Kerr and Ostrovsky, 2003; Pfeifer et al., 2012) thanks to their strong ability to cover, timely and repeatedly, wide and inaccessible areas, and to get high spatial and temporal resolution data (Alexakis et al., 2014; Yirsaw et al., 2017; Patel et al., 2019). Since the 1980s, multiple global LULC products (Table 1) have been derived from remotely sensed data, providing alternative characterizations of the Earth surface at varying extents of spatial and temporal resolutions (Townshend et al., 1991; Loveland et al., 2000; Bartholome and Belward, 2005).

One of the most important limitations of global LULC products is the within-product variability of accuracy (across different years, regions, and LULC types), besides the generally low agreement among products in many regions of the world (Tsendbazar et al., 2015b, 2016; Gao et al., 2020; Gong et al., 2013; Zimmer-Gembeck and Helfand, 2008). Such lack of consensus can translate into huge implications for subsequent global assessments of biodiversity status, carbon balance, or climate change (Estes et al., 2018; de la Cruz et al., 2017). In addition, accuracy at the local level can be too low, which impedes the use of global or regional LULC products in local studies (Hoskins et al., 2016; Tsendbazar et al., 2016), since it can lead to different conclusions due to the compelling amount of inconsistencies, uncertainties, and inaccuracies (Tsendbazar et al., 2015a; Estes et al., 2018). Multiple methodological reasons lay behind these discrepancies among LULC products (Congalton et al., 2014; Grekousis et al., 2015; Gómez et al., 2016): 
Table 1. Description of the GEE Global LULC products used in this study.

\begin{tabular}{|c|c|c|c|c|c|c|c|c|}
\hline $\begin{array}{l}\text { Product } \\
\text { ID(s) }\end{array}$ & Product & Version & Provider & Sensor & $\begin{array}{l}\text { Satellite or } \\
\text { Spaceborne }\end{array}$ & $\begin{array}{l}\text { Spatial } \\
\text { resolution }\end{array}$ & $\begin{array}{l}\text { Acquisition } \\
\text { time }\end{array}$ & Data type \\
\hline P1:P5 & $\begin{array}{l}\text { MCD12Q1 } \\
\text { (Type } 1 \text { to } 5 \text { ) }\end{array}$ & v6 & $\begin{array}{l}\text { NASA LP DAAC at the } \\
\text { USGS EROS Center }\end{array}$ & MODIS & Aqua, Terra & $500 \mathrm{~m}$ & 2001-2019 & $\begin{array}{l}\text { Image collection } \\
\text { over years }\end{array}$ \\
\hline P6 & CGLS-LULC100 & v3.0.1 & $\begin{array}{l}\text { Copernicus Global } \\
\text { Land Service (CGLS) }\end{array}$ & - & PROBA-V & $100 \mathrm{~m}$ & $2015-2019$ & $\begin{array}{l}\text { Image collection } \\
\text { over years }\end{array}$ \\
\hline P7 & GFCC & v3 & $\begin{array}{l}\text { NASA LP DAAC at } \\
\text { the USGS EROS Center }\end{array}$ & Multi-sensor & Multi-satellite & $30 \mathrm{~m}$ & $\begin{array}{r}2000,2005, \\
2010,2015\end{array}$ & $\begin{array}{l}\text { Image collection } \\
\text { over years }\end{array}$ \\
\hline P8 & GLOBCOVER & $v 2$ & $\begin{array}{l}\text { ESA and by the Catholic } \\
\text { University of Louvain }\end{array}$ & MERIS & ENVISAT & $300 \mathrm{~m}$ & 2009 & Single Image \\
\hline P9 & GFSAD & v0.1 & $\begin{array}{l}\text { Global Food Security } \\
\text { support Analysis Data at } \\
\text { 30m Project (GFSAD30) }\end{array}$ & Multi-sensor & Multi-satellite & $1000 \mathrm{~m}$ & 2010 & Single Image \\
\hline $\mathrm{P} 10$ & PALSAR2 & vfnf & JAXA EORC & SAR & ALOS, ALOS 2 & $25 \mathrm{~m}$ & $\begin{array}{l}2007-2010 \\
2015-2017\end{array}$ & Single Image \\
\hline $\mathrm{P} 11$ & HANSEN & $\mathrm{v} 1.7$ & $\begin{array}{l}\text { Hansen, UMD, Google, } \\
\text { USGS, NASA }\end{array}$ & OLI & Landsat 8 & 1 arc seconds & 2000-2019 & Single Image \\
\hline $\mathrm{P} 12$ & GFCH & v2005 & NASA, JPL & - & Lidar & 30 arc seconds & 2005 & Single Image \\
\hline $\mathrm{P} 13$ & $\begin{array}{l}\text { JRC Yearly History } \\
(\mathrm{YH})\end{array}$ & $\mathrm{v} 1.2$ & EC JRC, Google & Multi-sensor & Landsat $(5,7,8)$ & $30 \mathrm{~m}$ & 1984-2019 & Single Image \\
\hline $\mathrm{P} 14$ & $\begin{array}{l}\text { JRC Global Surface } \\
\text { Water (GSW) }\end{array}$ & $\mathrm{v} 1.2$ & EC JRC, Google & Multi-sensor & Landsat $(5,7,8)$ & $30 \mathrm{~m}$ & 1984-2019 & $\begin{array}{l}\text { Image collection } \\
\text { over years }\end{array}$ \\
\hline $\mathrm{P} 15$ & Tsinghua FROM-GLC & v10 & Tsinghua University & Multi-sensor & Landsat & $30 \mathrm{~m}$ & $1985-2018$ & Single Image \\
\hline
\end{tabular}

- Satellite sensors: the spatial, temporal and spectral resolutions of the source satellite images strongly determine the precision and accuracy of derived LULCs. Native pixel size can vary from dozens of meters to kilometers, which determines the precision. Revisiting frequency can vary from daily images to several weeks, which determines the possibility of removing cloud and atmospheric noise effects. In addition, the greater the number of spectral bands in a sensor, the greater the amount of complementary information that can help to differentiate among LULC classes.

- Processing techniques: the different algorithms for atmospheric correction, cloud filtering, image composition, viewing geometry corrections, etc. can also influence LULC accuracy.

- Acquisition year(s): some LULC products just refer to a particular year while others are regularly updated.

- Classification schemes: LULC legends can greatly differ in the number of classes and typology definitions. In general, 
- Classification algorithms: the approaches and rules used to identify each LULC have evolved from decision trees, to multivariate clustering, and machine learning, including now deep learning.

- Validation techniques of the final product. The amount and global distribution of ground truth samples differs across products and influences their reported accuracy.

Many efforts have been made to assess, compare, and harmonize the increasing plethora of global, regional and local LULC products, including their integration into synthetic products, which has shed light onto their strengths and weaknesses (Feng and Bai, 2019; Zhang et al., 2019; Gao et al., 2020; Liu et al., 2021). Still, the myriad of existing products with different specifications and accuracies have made their selection by the users problematic, and discouraging because it is frequently unknown whether a product meets the user needs for a particular area or LULC class (Tsendbazar et al., 2015b; Xu et al., 2020). In addition, many of these efforts are either limited to regional or national scale (e.g. Pérez-Hoyos et al. (2012); Gengler and Bogaert (2018)), coarse spatial resolution (e.g. Tuanmu and Jetz (2014); Jung et al. (2006)), or just one LULC type (e.g. Fritz et al. (2011)). The use of synergistic products takes advantage from the strengths of individual products while attenuating their respective weaknesses. However, they still face the challenge of taking into consideration the heterogeneity within pixels (spatial purity), i.e., they only provide a single discrete class per pixel (Tuanmu and Jetz, 2014), and of considering land cover change over time (temporal purity), i.e., they do not integrate the inter-annual variability while combining the related products. In general, given a target maximum error of 5-15\% either per class or for the overall accuracy, most of the current global land-cover maps still do not meet the accuracy demands of many applications (Liu et al., 2021).

In parallel to these efforts, deep artificial neural networks, also known as Deep Learning (DL) models, have shown impressive performance in computer vision and promising ones in remote sensing during the last decade. Currently, two specific types of DL models, i.e., CNNs (Convolutional Neural Networks) and RNNs (Recurrent Neural Networks), constitute the state-of-art in respectively extracting spatial and temporal patterns from data-records. Indeed, DL models are showing great performance in LULC tasks such as scene classification (Zhang et al., 2018a), object detection (Zhao et al., 2015; Guirado et al., 2021) and segmentation (Zhao and Du, 2016; Guirado et al., 2017; Safonova et al., 2021) in RGB and multi-spectral satellite and aerial images. However, such good performance is only possible when DL models are trained on smart data. The concept of smart data involves all pre-processing methods that improve value and veracity of data and of associated expert annotations (Luengo et al., 2020), resulting in high quality and accurately annotated datasets. In general, remote sensing datasets contain noise, missing values, and high variability and complexity across space, time and spectral bands. Applying pre-processing methods, such as gap filling and noise reduction to data and consensus across multiple sources to annotations, contributes to creating smart remote sensing datasets.

Currently, there only exist few multi-spectral datasets annotated for training DL models to map LULC and LULC change (Table 2). However, most of these datasets provide very short time series of data, very few LULC classes, and do not have a global coverage. As far as we know, there is no dataset designed for DL models that allows for global scale analysis of many LULC classes and that are long enough to characterize change over time, such as phenology, inter-annual dynamics, trends, anomalies, and abrupt changes. 
https://doi.org/10.5194/essd-2021-253

Preprint. Discussion started: 12 October 2021

(c) Author(s) 2021. CC BY 4.0 License.

(c) (i)

Table 2. A list of existing times series dataset, including the proposed TimeSpec4LULC dataset, for training machine learning models.

\begin{tabular}{|c|c|c|c|c|c|c|c|c|c|}
\hline Dataset & Source & $\#$ images $\times$ (pixels) & $\begin{array}{c}\text { Spatial } \\
\text { Resolution } \\
\text { (m) }\end{array}$ & $\begin{array}{l}\text { Temporal } \\
\text { Resolution }\end{array}$ & $\begin{array}{c}\text { No. } \\
\text { Bands }\end{array}$ & $\begin{array}{c}\text { No. } \\
\text { Classes }\end{array}$ & Extent & Intra/Inter time series & labeled for \\
\hline $\begin{array}{l}\text { CaneSat } \\
\text { (Virnodkar et al., 2020) }\end{array}$ & Sentinel-2 & $1627 \times(10 \times 10)$ & 10 & Monthly & 6 & 2 & India & {$[2018,2019]$} & $\begin{array}{l}\text { Sugarcane } \\
\text { classification }\end{array}$ \\
\hline $\begin{array}{l}\text { SpaceNet-7 } \\
\text { (Van Etten et al., 2021) }\end{array}$ & $\begin{array}{l}\text { Dove Satellite } \\
\text { Constellation } \\
\text { Planet Labs' }\end{array}$ & $24 \times(1024 \times 1024)$ & 4 & Monthly & 8 & 2 & 100 cities & {$[2017,2020]$} & $\begin{array}{l}\text { Buildings } \\
\text { tracking }\end{array}$ \\
\hline $\begin{array}{l}\text { Time series } \\
\text { spectral dataset for } \\
\text { croplands in France } \\
\text { (Hubert-Moy et al., 2019) }\end{array}$ & $\begin{array}{l}\text { MODIS and } \\
\text { LPIS }\end{array}$ & 21,129 pixels & 250 & 8-day intervals & 4 & 19 & France & [2006, 2017] & $\begin{array}{l}\text { Crop type } \\
\text { mapping }\end{array}$ \\
\hline TiSeLaC $^{1}$ & Landsat & $8 \times(2866 \times 2633)$ & 30 & Annually & 10 & 9 & The Reunion Island & 2014 & classification \\
\hline $\begin{array}{l}\text { BreizhCrops } \\
\text { Rußwurm et al. (2019) }\end{array}$ & Sentinel-2 & 610,000 pixels & 60 & - & 10 & 9 & $\begin{array}{l}\text { Brittany dept. } \\
\text { France }\end{array}$ & {$[01 / 01 / 2017,31 / 12 / 2017]$} & $\begin{array}{l}\text { Crop type } \\
\text { mapping }\end{array}$ \\
\hline $\begin{array}{l}\text { TimeSpec4LULC } \\
\text { (Ours) }\end{array}$ & MODIS & $11,856,992$ pixels & 500 & Monthly & 7 & 29 & Global & {$[07 / 2002,01 / 2021]$} & $\begin{array}{l}\text { LULC mapping } \\
\text { and change detection }\end{array}$ \\
\hline
\end{tabular}

This paper presents, TimeSpec4LULC, a new open-source, smart and global dataset of multi-spectral time series targeted towards the development and evaluation of DL models to map LULCs and monitor their change globally. TimeSpec4LULC was built using Google Earth Engine (GEE) by combining the seven 500m spectral bands of MODIS Aqua and MODIS Terra satellite sensors at a monthly time step from 2002 to 2021. It contains 11.85 million of pixels that were annotated based on a consensus across up to 15 global LULC products (Table 1) for 29 broad and globally harmonized LULC classes. In addition, it provides this metadata at pixel level: geographic coordinates, country and departmental divisions, spatio temporal consistency across LULC products, statistics on temporal data availability, and the global human modification index. The annotation quality was further assessed by experts using Google Satellite and Bing Maps very high resolution images in 100 samples per class evenly distributed around the world.

\section{Methods}

To build TimeSpec4LULC, we first determined the spatial and temporal agreement across 15 heterogeneous global LULC products (listed in Table 1) for 29 broad and globally harmonized LULC classes. Then, for each class, we extracted a 19-year monthly time series for the seven 500-meter spectral bands of MODIS Terra and Aqua combined. We carried out this process in GEE (Gorelick et al., 2017) since it provides access to freely available satellite imagery under a unified programming, processing and visualization environment.

\subsection{Finding spatial agreement across 15 global LULC products}

To find the spatial consensus across global LULC products for different LULC classes, we followed five steps: 1) selection of global LULC products, 2) standardization and harmonization of LULC legends, 3) combination of products across space and 
https://doi.org/10.5194/essd-2021-253

Preprint. Discussion started: 12 October 2021

(c) Author(s) 2021. CC BY 4.0 License.

(c) (1)

time, and 4) reprojection and selection of spatial purity thresholds to get a final consistent mask across the 15 products for each one of the 29 LULC classes.

\subsubsection{Selection of global LULC products}

We used the 15 most updated global LULC products available in GEE (Table 1). These products widely differ in their source satellite data, spatial resolution, temporal coverage, class legend, and accuracy. Given such heterogeneity, we used the consensus across all of them in space and time as a source of reliability to support our annotation. That is, a given LULC class is assigned to a $500 \mathrm{~m}$ pixel only if it was consistent over time and space across all the 15 LULC products.

\subsubsection{Standardization and Harmonization of LULC legends}

Broadly, land cover (LC) refers to the different vegetation types (usually following biotype, plant functional type, or physiognomy schemes, such as forests, shrublands, or grasslands) or other biophysical classes (such as water bodies, snow, or bare soil) that cover the Earth's surface. Whereas, land use (LU) describes the set of human activities that significantly modify a LC (such as urban areas and croplands).

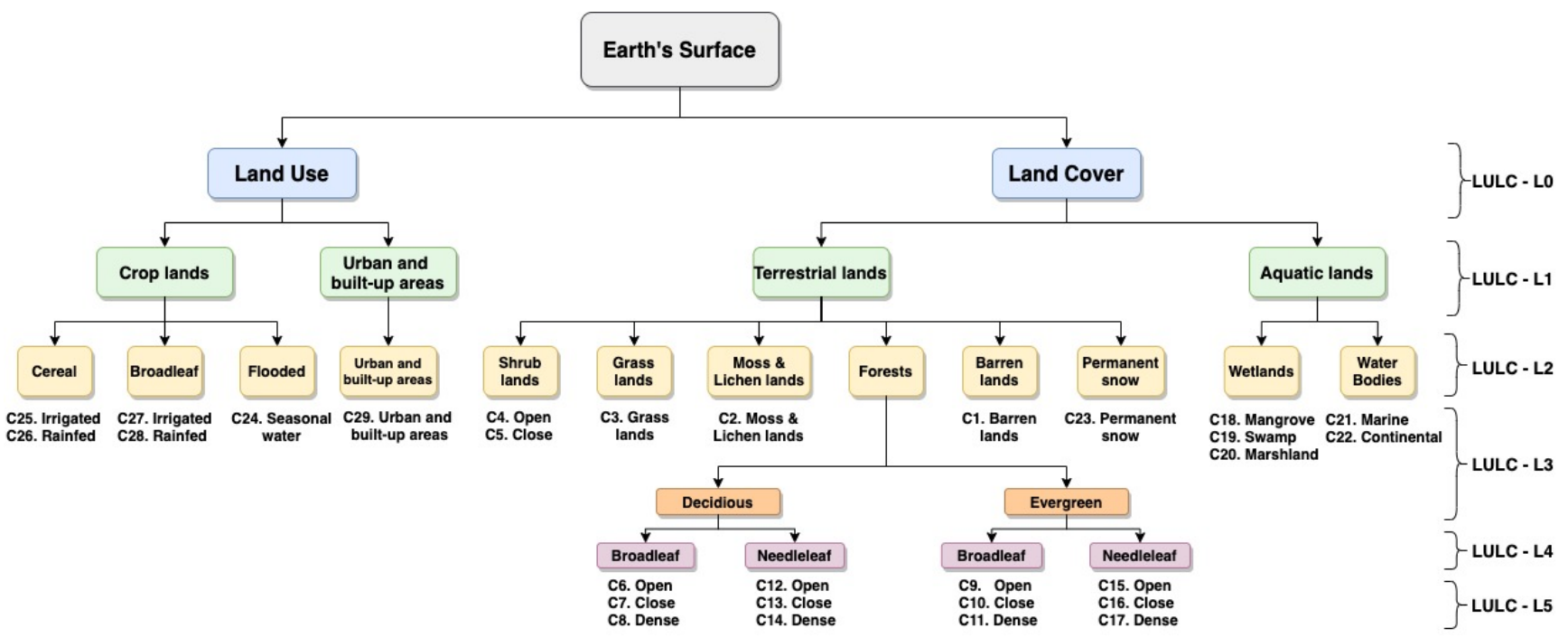

Figure 1. The hierarchical structure of the LULC classes contained in the TimeSpec4LULC dataset. C1 to C29: class 1 to class 29. LULC-L0 to LULC-L5: LULC level 0 to LULC level 5. The level LULC-L0 includes the 2 blue boxes. The level LULC-L1 includes the 4 green boxes. The level LULC-L2 includes the 12 yellow boxes. The level LULC-L3 includes all the classes of the 12 yellow boxes (from C1 to C5 and from C18 to C29) except the Forests class where it includes only the 2 orange boxes (Decidious and Evergreen). The level LULC-L4 includes the same classes but expands the Forests class into the 4 purple boxes: Decidious (Broadleaf and Needleleaf) and Evergreen (Broadleaf and Needleleaf). The last level LULC-L5 includes all the 29 LULC classes (from C1 to C29). 
To standardize and harmonize the LULC legends across the 15 LULC products, we used expert knowledge (Vancutsem et al., 2013) to create a common nomenclature of 29 broad classes (6 LU classes and 23 LC classes) that were interoperable across all products (see the hierarchical structure of our legend in Fig. 1 and the rule set across products in Table 3). The LULC legend was structured into 6 hierarchical levels (L0 to L5).

The six anthropogenic LU classes contained Urban and built-up areas and five types of croplands. The 23 natural or seminatural LC classes covered three aquatic systems (Marine water bodies, Continental water bodies, and Wetlands) and 18 terrestrial systems (Permanent snow, Barren lands, Moss and Lichen lands, Grasslands, Close Shrublands, Open Shrublands, and 12 types of Forests that differed in their canopy type, phenology and tree cover).

Table 3. The rule set used to build the LULC legend for TimeSpec4LULC dataset. P1 to P15: product 1 to 15 . C1 to C29: class 1 to class 29 . The numbers from 0 to 220 correspond to the class label in GEE. NU: Not Used, NA: Not Available, TC: Tree Cover, G: Gain, L: Loss, D: Datamask, TH: Tree Hight, TCC: Tree Canopy Cover, TCF: Tree-Cover Fraction, and SCF: Shrub-Cover Fraction)

\begin{tabular}{|c|c|c|c|c|c|c|c|c|c|c|c|c|c|c|c|}
\hline & P1 & $\mathrm{P} 2$ & P3 & P4 & P5 & P6 & P7 & P8 & P9 & P10 & P11 & P12 & P13 & P14 & P15 \\
\hline $\mathrm{C} 1$ & 16 & 15 & NA & 7 & 11 & 60 & $T C C<10$ & 200 & 0 & 2 & $(T C<10) \cap(G=0) \cap(L=0) \cap(D \neq 2)$ & $T H<1$ & $1 \cup 0$ & 0 & $\operatorname{Not}(\geq 1)$ \\
\hline $\mathrm{C} 2$ & 16 & 15 & NA & 7 & 11 & 100 & $T C C<10$ & $200 \cup 150$ & 0 & 2 & $(T C<10) \cap(G=0) \cap(L=0) \cap(D \neq 2)$ & $T H<1$ & $1 \cup 0$ & 0 & $\operatorname{Not}(\geq 1)$ \\
\hline $\mathrm{C} 3$ & 10 & 10 & 1 & 6 & 6 & 30 & $T C C<10$ & 140 & $\mathrm{NA}$ & 2 & $(T C<10) \cap(G=0) \cap(L=0) \cap(D \neq 2)$ & $T H<2$ & $1 \cup 0$ & 0 & $\operatorname{Not}(\geq 1)$ \\
\hline $\mathrm{C} 4$ & 7 & 7 & 2 & NA & 5 & $20 \cup(10<S C F<50)$ & $T C C<10$ & 150 & 0 & 2 & $(T C<10) \cap(G=0) \cap(L=0) \cap(D \neq 2)$ & $T H<2$ & $1 \cup 0$ & 0 & $\operatorname{Not}(\geq 1)$ \\
\hline C5 & 6 & 6 & 2 & NA & 5 & $20 \cup(S C F>50)$ & $T C C<10$ & 130 & 0 & 2 & $(T C<10) \cap(G=0) \cap(L=0) \cap(D \neq 2)$ & $T H<2$ & $1 \cup 0$ & 0 & $\operatorname{Not}(\geq 1)$ \\
\hline C6 & NA & NA & NA & 4 & 4 & $4+(15<T C F<30)$ & $15<T C C<30$ & 60 & NA & 1 & $(15<T C<30) \cap(G=0) \cap(L=0) \cap(D \neq 2)$ & $T H>2$ & $1 \cup 0$ & 0 & $\operatorname{Not}(\geq 1)$ \\
\hline $\mathrm{C} 7$ & NA & NA & NA & 4 & 4 & $4+(40<T C F<60)$ & $40<T C C<60$ & 50 & NA & 1 & $(40<T C<60) \cap(G=0) \cap(L=0) \cap(D \neq 2)$ & $T H>2$ & $1 \cup 0$ & 0 & $\operatorname{Not}(\geq 1)$ \\
\hline $\mathrm{C} 8$ & 4 & 4 & 6 & 4 & 4 & $4+(T C F>60)$ & $T C C>60$ & 50 & NA & 1 & $(T C>60) \cap(G=0) \cap(L=0) \cap(D \neq 2)$ & $T H>2$ & $1 \cup 0$ & 0 & $\operatorname{Not}(\geq 1)$ \\
\hline C9 & NA & NA & NA & 3 & 3 & $3+(15<T C F<30)$ & $15<T C C<30$ & NA & NA & 1 & $(15<T C<30) \cap(G=0) \cap(L=0) \cap(D \neq 2)$ & $T H>2$ & $1 \cup 0$ & 0 & $\operatorname{Not}(\geq 1)$ \\
\hline $\mathrm{C} 10$ & NA & NA & NA & 3 & 3 & $3+(40<T C F<60)$ & $40<T C C<60$ & NA & NA & 1 & $(40<T C<60) \cap(G=0) \cap(L=0) \cap(D \neq 2)$ & $T H>2$ & $1 \cup 0$ & 0 & $\operatorname{Not}(\geq 1)$ \\
\hline C11 & 3 & 3 & 8 & 3 & 3 & $3+(T C F>60)$ & $T C C>60$ & NA & NA & 1 & $(T C>60) \cap(G=0) \cap(L=0) \cap(D \neq 2)$ & $T H>2$ & $1 \cup 0$ & 0 & $\operatorname{Not}(\geq 1)$ \\
\hline $\mathrm{C} 12$ & NA & NA & NA & 2 & 2 & $2+(15<T C F<30)$ & $15<T C C<30$ & 40 & NA & 1 & $(15<T C<30) \cap(G=0) \cap(L=0) \cap(D \neq 2)$ & $T H>2$ & $1 \cup 0$ & 0 & $\operatorname{Not}(\geq 1)$ \\
\hline $\mathrm{C} 13$ & NA & NA & NA & 2 & 2 & $2+(40<T C F<60)$ & $40<T C C<60$ & 40 & NA & 1 & $(40<T C<60) \cap(G=0) \cap(L=0) \cap(D \neq 2)$ & $T H>2$ & $1 \cup 0$ & 0 & $\operatorname{Not}(\geq 1)$ \\
\hline $\mathrm{C} 14$ & 2 & 2 & 5 & 2 & 2 & $2+(T C F>60)$ & $T C C>60$ & 40 & NA & 1 & $(T C>60) \cap(G=0) \cap(L=0) \cap(D \neq 2)$ & $T H>2$ & $1 \cup 0$ & 0 & $\operatorname{Not}(\geq 1)$ \\
\hline C15 & 9 & 9 & NA & 1 & 1 & $1+(15<T C F<30)$ & $15<T C C<30$ & 90 & NA & 1 & $(15<T C<30) \cap(G=0) \cap(L=0) \cap(D \neq 2)$ & $T H>2$ & $1 \cup 0$ & 0 & $\operatorname{Not}(\geq 1)$ \\
\hline C16 & 8 & 8 & 4 & 1 & 1 & $1+(40<T C F<60)$ & $40<T C C<60$ & 70 & NA & 1 & $(40<T C<60) \cap(G=0) \cap(L=0) \cap(D \neq 2)$ & $T H>2$ & $1 \cup 0$ & 0 & $\operatorname{Not}(\geq 1)$ \\
\hline $\mathrm{C} 17$ & 1 & 1 & 7 & 1 & 1 & $1+(T C F>60)$ & $T C C>60$ & 70 & NA & 1 & $(T C>60) \cap(G=0) \cap(L=0) \cap(D \neq 2)$ & $T H>2$ & $1 \cup 0$ & 0 & $\operatorname{Not}(\geq 1)$ \\
\hline $\mathrm{C} 18$ & 11 & 11 & NA & NA & NA & 90 & $T C C>10$ & 170 & NA & NA & $(T C>10) \cap(G=0) \cap(L=0) \cup(D=2)$ & $T H>2$ & $2 \cup 3$ & 1 & $\operatorname{Not}(\geq 1)$ \\
\hline C19 & 11 & 11 & NA & NA & NA & 90 & $T C C>10$ & $\begin{array}{l}a .160 \cup 180 \\
b . N o t(170)\end{array}$ & NA & NA & $(T C>10) \cap(G=0) \cap(L=0) \cup(D=2)$ & $T H>2$ & $2 \cup 3$ & 1 & $\operatorname{Not}(\geq 1)$ \\
\hline $\mathrm{C} 20$ & 11 & 11 & NA & NA & NA & 90 & $T C C<10$ & $\begin{array}{c}160 \cup 170 \\
\cup 180\end{array}$ & NA & NA & $(T C<10) \cap(G=0) \cap(L=0) \cup(D=2)$ & $T H<2$ & $2 \cup 3$ & 1 & $\operatorname{Not}(\geq 1)$ \\
\hline $\mathrm{C} 21$ & 17 & 0 & 0 & 0 & 0 & 200 & NA & 210 & NA & 3 & NA & NA & 3 & 1 & $\operatorname{Not}(\geq 1)$ \\
\hline $\mathrm{C} 22$ & 17 & 0 & 0 & 0 & 0 & 80 & NA & 210 & NA & 3 & NA & NA & 3 & 1 & $\operatorname{Not}(\geq 1)$ \\
\hline $\mathrm{C} 23$ & 15 & NA & NA & NA & 10 & 70 & NA & 220 & NA & NA & NA & NA & $1 \cup 0$ & 0 & $\operatorname{Not}(\geq 1)$ \\
\hline $\mathrm{C} 24$ & 12 & 12 & $3 \cup 1$ & $5 \cup 6$ & $7 \cup 8$ & 40 & NA & $11 \cup 14$ & $\begin{array}{c}1 \cup 2 \cup 3 \\
\cup 4 \cup 5\end{array}$ & NA & NA & NA & $2 \cup 3$ & $\begin{array}{l}0 \cup 4 \cup 5 \\
\cup 8 \cup 10\end{array}$ & $\operatorname{Not}(\geq 1)$ \\
\hline $\mathrm{C} 25$ & 12 & 12 & 1 & 6 & 7 & 40 & NA & 11 & $1 \cup 2$ & NA & NA & NA & $1 \cup 0$ & 0 & $\operatorname{Not}(\geq 1)$ \\
\hline $\mathrm{C} 26$ & 12 & 12 & 1 & 6 & 7 & 40 & NA & 14 & $3 \cup 4 \cup 5$ & NA & NA & NA & $1 \cup 0$ & 0 & $\operatorname{Not}(\geq 1)$ \\
\hline $\mathrm{C} 27$ & 12 & 12 & 3 & 5 & 8 & 40 & NA & 11 & $1 \cup 2$ & NA & NA & NA & $1 \cup 0$ & 0 & $\operatorname{Not}(\geq 1)$ \\
\hline $\mathrm{C} 28$ & 12 & 12 & 3 & 5 & 8 & 40 & NA & 14 & $3 \cup 4 \cup 5$ & NA & NA & NA & $1 \cup 0$ & 0 & $\operatorname{Not}(\geq 1)$ \\
\hline C29 & 13 & 13 & 10 & 8 & 9 & 50 & NA & 190 & NA & NA & NA & NA & $1 \cup 0$ & 0 & $\mathrm{NU}$ \\
\hline
\end{tabular}

\subsubsection{Combining products across time and space}

For each LULC class, we built a consensus image with its global distribution by agreement across the 12 LULC products (P1 to P12). For products that only contained one image (P1 to P7) referred to a particular year or period, we obtained a binary 
Table 4. Description of the Temporal-Spatial Combination of the 15 global LULC products (P1:P15) masks to build a consensus image for each LULC class. $\left({ }^{1}\right.$ : Inter-annual combination used in all products except in P13, where we first calculated the inter-annual Mean and then transformed it into a water no-water binary mask)

\begin{tabular}{|c|c|c|c|}
\hline Class Id(s) & LULC class(s) & Spatial Combination & Temporal Combination $^{1}$ \\
\hline $\mathrm{C} 1$ & Barren lands & Rule 1: Mean(P1: P12) *P13*P14* P15 & AND \\
\hline $\mathrm{C} 2$ & Moss and Lichen lands & Rule 2: Mean(P1 : P5, P7 : P12) * P6 * P13 * P14 * P15 & MEAN \\
\hline $\mathrm{C} 4$ & Open Shrublands & Rule 1: Mean(P1:P12)*P13*P14*P15 & AND \\
\hline $\mathrm{C} 5$ & Close Shrublands & Rule 1: Mean(P1:P12)*P13*P14*P15 & MEAN \\
\hline $\mathrm{C} 18$ & Mangrove Wetlands & Rule 3: Mean (P1 : P7, P9: P14) * P8 * P15 & MEAN \\
\hline $\mathrm{C} 19$ & Swamp Wetlands & Rule 4: Mean(P1 : P8.a, P9 : P12) * P8.b * P15 & MEAN \\
\hline $\mathrm{C} 20$ & Marshland Wetlands & Rule 5: Mean(P1 : P6, P8 : P10, P13: P14) * P7 * P11 * P12 * P15 & MEAN \\
\hline $\mathrm{C} 21: \mathrm{C} 22$ & Water Bodies & Rule 1: Mean $(\mathrm{P} 1: \mathrm{P} 12) * \mathrm{P} 13 * \mathrm{P} 14 * \mathrm{P} 15$ & AND \\
\hline $\mathrm{C} 23$ & Permanent Snow & Rule 1: Mean(P1 : P12) * P13* P14 * P15 & AND \\
\hline $\mathrm{C} 29$ & Urban and built-up areas & Rule 1: Mean(P1 : P12) * P13 * P14* P15 & AND \\
\hline
\end{tabular}

mask with the targeted LULC class as 1. As further explained below, for products that were a collection over years (P8 to P12), we first obtained a binary mask for each year and then produced their combination over years (Table 4). Then, we obtained the spatial agreement over these 12 masks and used two water bodies products (P13 and P14) and one impervious surface product (P15) to further refine the consensus.

The inter-annual combination of LULC masks was based on two types of rules according to the inter-annual consistency of some products for specific LULC classes. In general, the combination over time was done using the AND operator when handling classes with high temporal stability, namely Urban and built-up areas, water bodies, Permanent Snow, Croplands, Open Shrublands, Barren lands, and Grasslands. Alternatively, since some LULC products showed implausible inter-annual changes for specific classes (e.g., wetlands affected by droughts or large areas of no-forest cover in one year preceded and followed by forest in the previous and following years, respectively), to avoid unrealistic data loss, the MEAN operator was used in the following classes: Moss and Lichen lands, Forests, Close Shrublands, and Wetlands.

Afterwards, for each LULC class, a spatial combination of the 12 masks, one per product, was performed following six specific rules according to the global abundance of each class (Table 4). In general (Rule 1), the MEAN operator was used across products P1 to P12 and the result was multiplied by two water class masks (P13 and P14) to eliminate water pixels from land classes and land pixels from water classes, and by impervious surface class mask of P15 to eliminate impervious pixels from all classes but urban. More relaxed rules where applied to five LULC classes that had too few pixels (less than 1000) with the general rule (see details in Table 4). The application of the explained spatio-temporal combination resulted in a mask for 
https://doi.org/10.5194/essd-2021-253

Preprint. Discussion started: 12 October 2021

(c) Author(s) 2021. CC BY 4.0 License.

(c) (i)

each LULC class produced at the resolution of the finest product (i.e., $30 \mathrm{~m}$ ), where each pixel had a consensus level value $p$ in $[0,1]$. Hence, $p$ indicates the consensus degree for a pixel to belong to the class represented by each LULC mask.

\subsubsection{Re-projection and Selection of purity threshold}

The 30-meter resolution LULC consensus was reprojected to MODIS resolution (approximately equal to $500 \mathrm{~m}$ ) using the spatial MEAN reducer. This $500 \mathrm{~m}$ average consensus was used to explore different pixel-purity thresholds $\theta$ for each LULC class. We kept $\theta=1$, when the number of 500-meter pixels retrieved was greater than 1000 , which meant that those pixels were $100 \%$ pure for that class. When the number of these pixels was lower than 1000 at $\theta=1$, we decreased $\theta$ to $0.75 \%$, which meant that up to $25 \%$ of the pixel could be occupied by another LULC class. In any case, our dataset provides as metadata at pixel level, the spatial purity percentage, so the user can control the desired purity and subsequent sample size (Table 6).

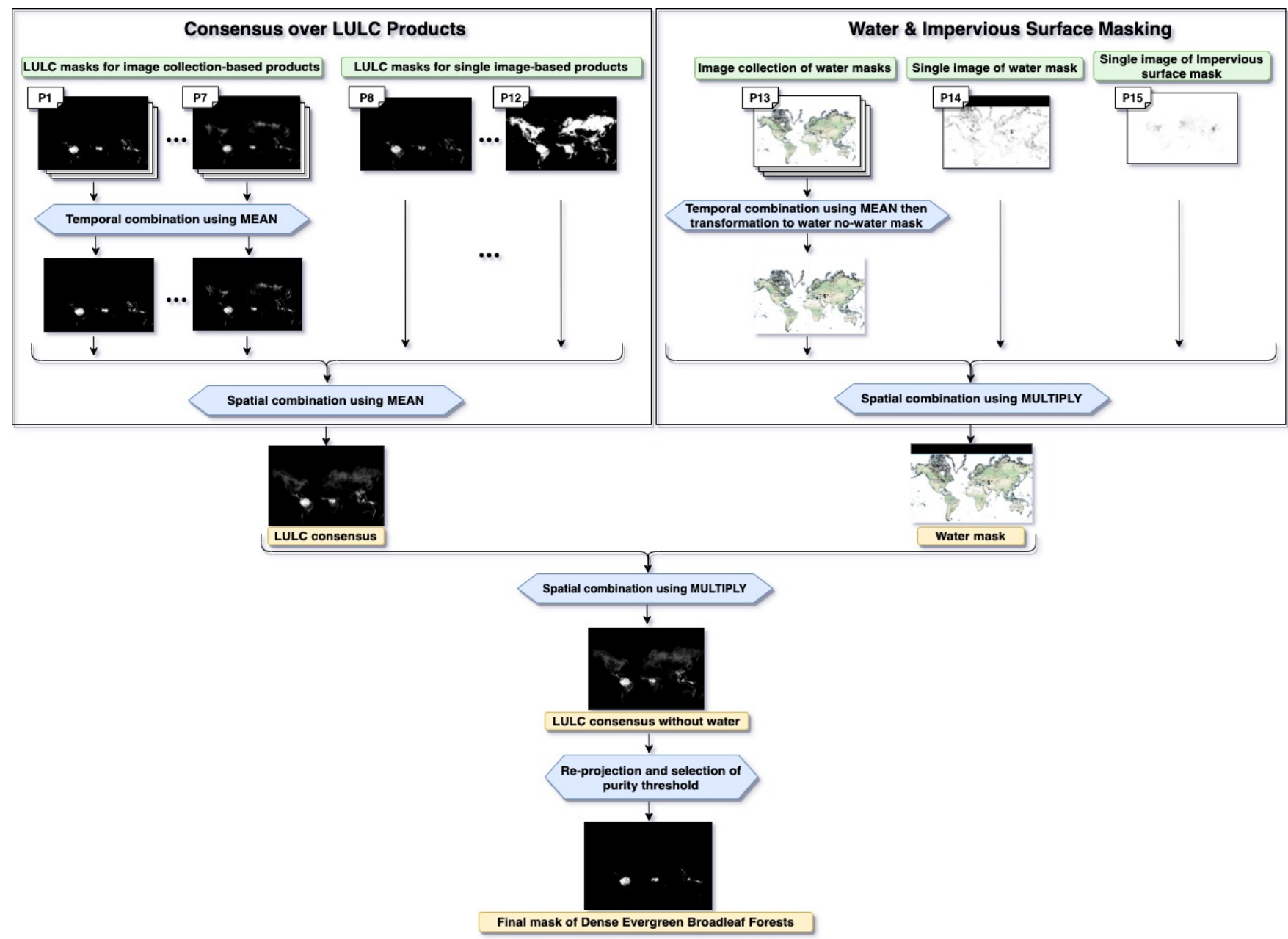

Figure 2. Example of the final mask creation process for the Dense Evergreen Broadleaf Forests LULC class produced through the spatial agreement over the 15 global LULC products available in GEE. 
https://doi.org/10.5194/essd-2021-253

Preprint. Discussion started: 12 October 2021

(c) Author(s) 2021. CC BY 4.0 License.

(c) (i)

To clarify the process of spatial agreement creation across the 15 global LULC products, we provide an example explaining the final mask creation for the class Dense Evergreen Broadleaf (Fig. 2). After performing the spatial agreement process for each LULC class, we combined the final class masks for all the 29 LULC classes to generate one global LULC map describing their distribution (Fig. 3).

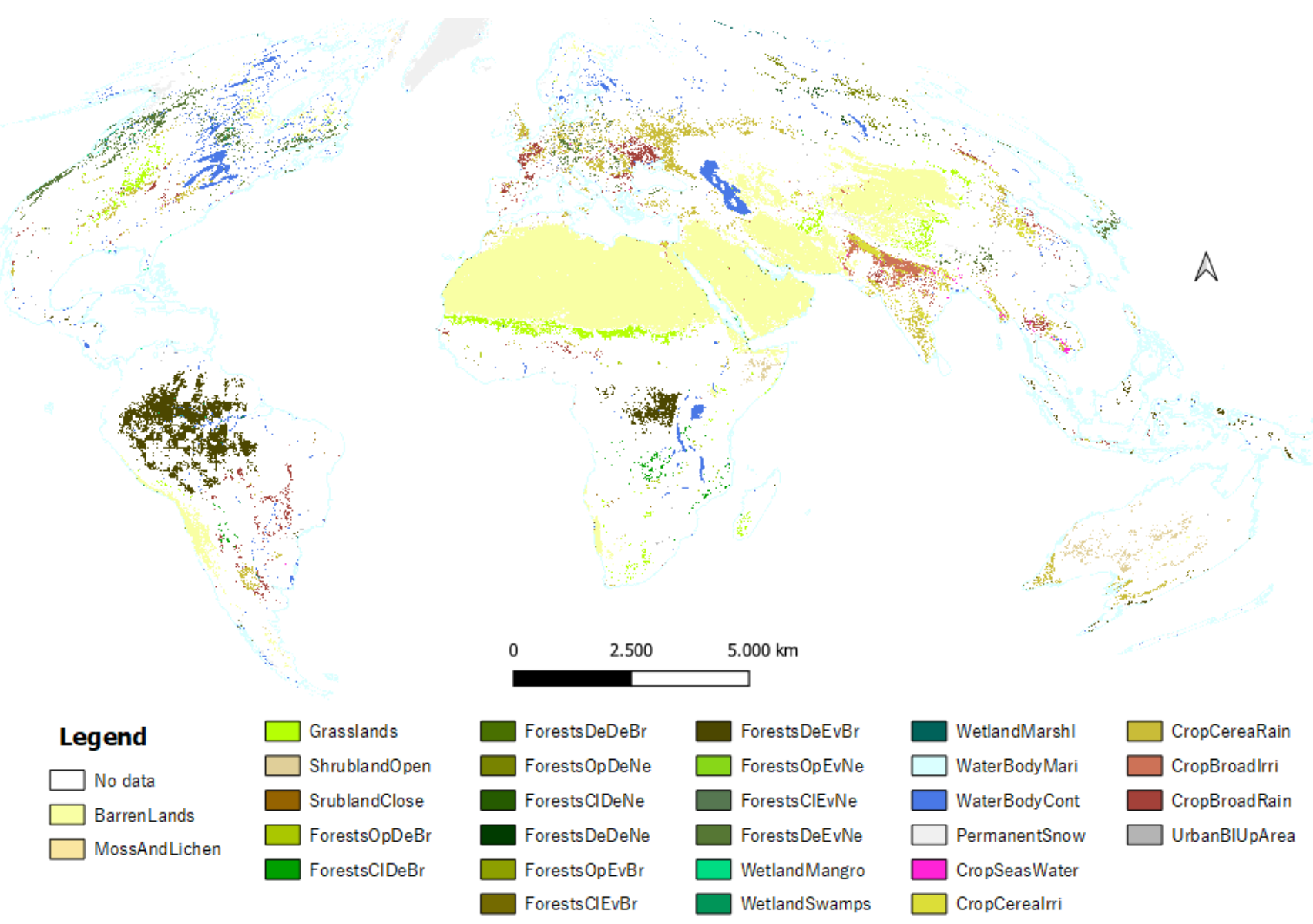

Figure 3. Distribution of the number of covered countries (FAO-L0) over the 29 LULC classes. This map combines all the LULC classes maps that were generated from the process of spatial agreement across the 15 global LULC products available in GEE.

\subsection{Extracting times series of spectral data for 29 LULC classes globally}

To extract the 19-year monthly time series of the seven 500-meter MODIS spectral bands for each of the 29 LULC classes throughout the entire world, we followed four steps (Fig. 4): 1) spatio-temporal filtering of Terra and Aqua data based on Quality Assessment flags, 2) aggregating the original 8-day Terra and Aqua data into monthly composites, 3) merging the two monthly time series into a Terra+Aqua Combined time series, and 4) data extraction and archiving (Fig. 5). 


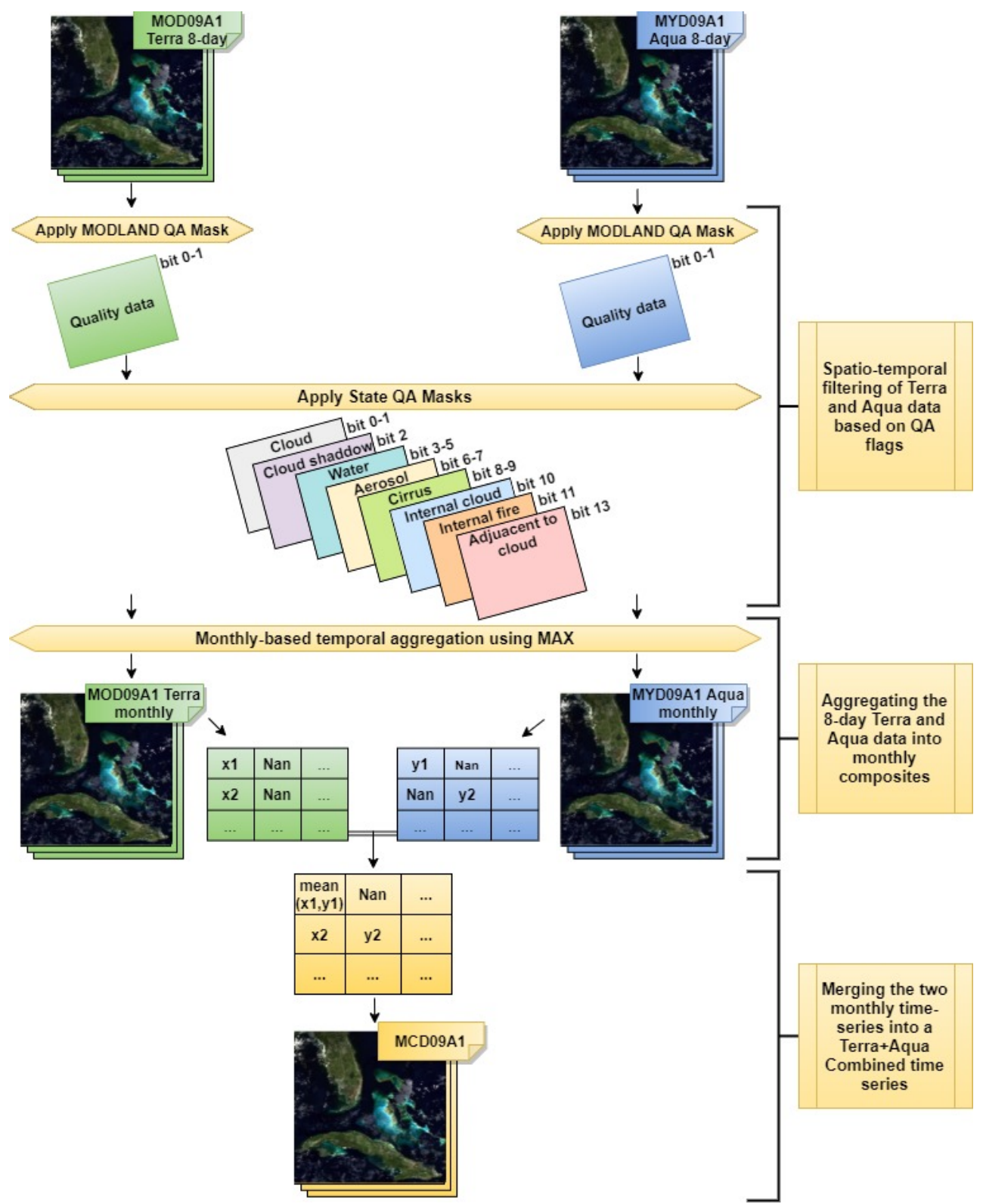

Figure 4. Description of the spatio-temporal filtering of Terra and Aqua, their aggregation into monthly composites, and their merging into Terra+Aqua Combined time series. This process aims to filter out spectral values affected by disruptive conditions, and to reduce the number of gaps in the multi-spectral time series for the 29 LULC classes.

\subsubsection{Spatio-temporal filtering of Terra and Aqua data based on Quality Assessment flags}

MODIS sensor is known by its high temporal coverage ensured by Terra and Aqua satellites, and by its innovative features (spectral, spatial, and temporal) that are highly suitable for LULC mapping and change detection (García-Mora et al., 2012; 
https://doi.org/10.5194/essd-2021-253

Preprint. Discussion started: 12 October 2021

(c) Author(s) 2021. CC BY 4.0 License.

(c) (i)

Xiong et al., 2017). Thus, we used two MODIS products MOD09A1 and MYD09A1 that estimate the 8-day surface spectral reflectance for the seven 500-meter bands from Terra and Aqua, respectively. Since Aqua was launched three years later (in 2002) after Terra had been launched, the acquisition time of our dataset is from 2002-07-04 to 2021-01-25.

The quality of any time series of satellite imagery is affected by the internal malfunction of satellite sensors, atmospheric (e.g., clouds, shadows, cirrus, etc.) or land (e.g., floods, snow, fires, etc.) conditions. In addition to the spectral bands, MODIS products provide 'Quality Assessment' (QA) flags as metadata bands to allow the user to filter out spectral values affected by disruptive conditions. Therefore, all QA flags were used to remove noise, spurious values, and outliers in the image collection. "MODLAND QA" flags (bits 0-1) were used to only select pixel values produced at 'ideal quality'. Then, "State QA" flags were used to mask out clouds (bits 0-1), internal clouds (bit 10), pixels adjacent to clouds (bit 13), cirrus (bits 8-9), cloud shadows (bit 2), high aerosol quantities (bits 6-7), and internal fires (bit 11). Regarding the water flag (bits 3-5), it was used to mask out water pixels in terrestrial systems (but not in Permanent Snow, and in Croplands flooded with seasonal water).

\subsubsection{Aggregating the original 8-day Terra and Aqua data into monthly composites}

Filtering the MODIS Terra and Aqua data records produced many missing-value gaps in their 8-day time series. To overcome this issue and further reduce the presence of noise in our dataset, the original 8-day time series were aggregated into monthly composites by computing the maximum over the observations of each month. Indeed, despite reducing the temporal resolution from 8-day to monthly composites shortened the time series size, it generated two datasets with less missing values and clear monthly patterns, which are more intuitive to track LULC dynamics than the 8-day patterns.

\subsubsection{Merging the two monthly time series into a Terra+Aqua Combined time series}

Terra satellite daily orbits above the Earth's surface from north to south in the morning at around 10:30 local time, while Aqua orbits in the opposite direction in the afternoon at around 13:30. Having two opportunities per day at each location increases the chances of capturing an image under good atmospheric conditions. To further reduce the number of missing values in our dataset, we merged the monthly time series provided by these two satellites into a Terra+Aqua Combined time series. That is, for each pixel and month, when both Terra and Aqua had values, we used the mean between them; when one satellite had a missing value, we used the available one; and when both of them had missing values, the combined value remains missing.

\subsubsection{Data extraction and archiving}

One of the biggest advantages of our dataset is its global scale characteristic since all the LULC classes data were extracted globally from all regions over the world. To take into account all the differences across the globe and thinking of regional interests that users could have, for each LULC class we organized the dataset into two levels. We used the Food and Agricultural Organization's (FAO's) Global Administrative Unit Layers (GAUL) product available in GEE to arrange our dataset into FAO-L0 (i.e., countries) and FAO-L1 (i.e., departments, states, provinces). For all 500-meter pixels selected at each FAOL1 administrative unit, we retrieved the time series of the 7 spectral bands, together with the LULC class code and name, 
pixel id, pixel purity percentage, percentage of non-missing data per band throughout the time series, average Global Human Modification index (gHM), and the latitude and longitude of the pixel center. Average gHM was derived as the spatial mean projected to MODIS resolution of the gHM (Kennedy et al., 2019) product available in GEE, which provides a cumulative measures of human modification of terrestrial lands. Finally, we exported the 7-band time series of each FAO-L1 unit and structured it as explained in section 3.

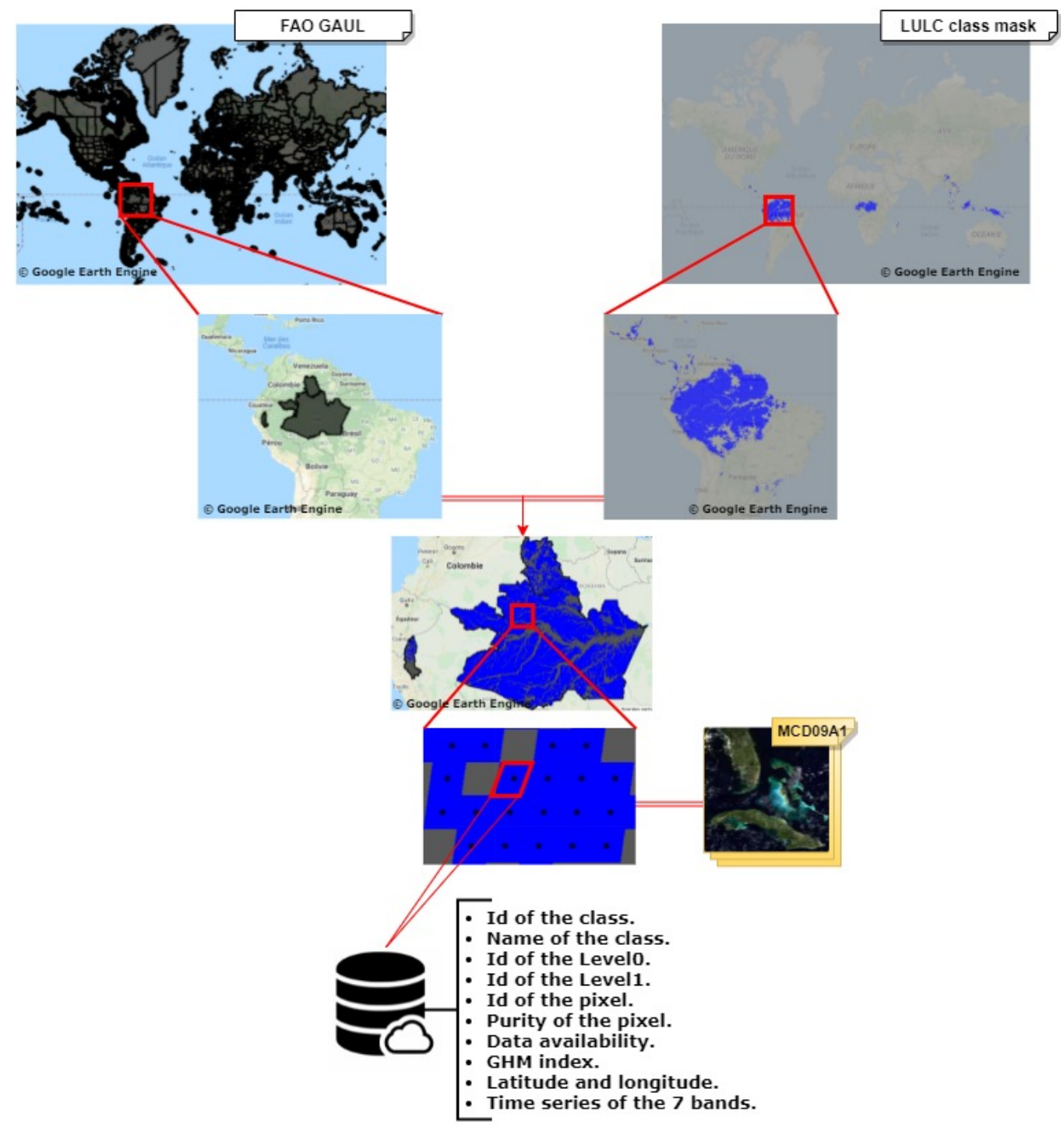

Figure 5. Description of the data extraction process for the LULC class Dense Evergreen Broadleaf Forests. It consists in looping over all the world's countries (FAO-L0) and departments (FAO-L1) that intersect with this LULC class mask. Then, it extracts the time series of the seven spectral bands of MODIS (MCD09A1-monthly-500m) along with a set of metadata at the pixel level. 


\section{Data}

To organize and assess the quality of the extracted global data for all the 29 LULC classes, we first present the description of the dataset structure stored in the repository ${ }^{2}$ (Khaldi et al., 2021), then we evaluate the quality of its annotation process.

\subsection{Data structure description}

TimeSpec4LULC is provided in 30 different ZIP files owning the name of the 29 LULC classes (The Barren Lands class is divided into two files since it is too large). Within each ZIP file, there exists a set of seven CSV files, each one corresponding to one of the seven spectral bands. The naming of each file follows this structure: IdOfTheClass_NameOfTheClass_ModisBand.csv For example, for band 1 of the Barren Lands class, the filename is: 01_BarrenLands_MCD09A1b01.csv

Inside each CSV file, rows represent the collected pixels for that class. The first 11 columns contain the following metadata:

- "IdOfTheClass": Id of the class.

- "NameOfTheClass": Name of the class.

— "IdOfTheLevel0": Id of the FAO-L0 (i.e., countries).

_ "IdOfTheLevel1": Id of the FAO-L1 (i.e., departments, states, or provinces depending on the country).

- "IdOfThePixel": Id of the pixel.

- "PurityOfThePixel": Spatial and inter-annual consensus for this class across multiple land-cover products, i.e., purity of the pixel.

- "DataAvailability": percentage of non-missing data per band throughout the time series.

- "Index_GHM": average of Global Human Modification index (gHM).

- "Lat": Latitude of the pixel center.

- "Lon": Longitude of the pixel center.

- “.geo": (Longitude, Latitude) of the pixel center with more precision.

And, the last 223 columns contain the 223 monthly observations of the time series for one spectral band from 2002-07 to 2021-01. Along with the dataset, an Excel file named 'Countries_Departments_FAO-GAUL' containing the FAO-L0 and the FAO-L1 Ids and names (following the FAO-GAUL standards) is provided.

\footnotetext{
${ }^{2}$ https://zenodo.org/record/5020024.YWARotpBxaQ
} 
https://doi.org/10.5194/essd-2021-253

Preprint. Discussion started: 12 October 2021

(c) Author(s) 2021. CC BY 4.0 License.

(c) (i)

\subsection{Data quality control}

The quality of the dataset annotation was assessed and validated visually by two co-author experts using two very high resolution imagery $\left(<1 \mathrm{~m} /\right.$ pixel) sources, namely Google Earth and Bing Maps imagery ${ }^{3}$. The assessment process includes three stages.

- First, a set of 100 samples is carefully selected from each class following the minimum distance criteria. That is, depending on the overall size of LULC class, the pixels within a minimum distance with respect to each pixel are eliminated until getting 100 pixels evenly distributed over the globe. Fig. 6 shows the distribution of the 2,900 selected pixels.

- Second, the class of each pixel of the $29 \times 100$ samples is identified visually by the expert eye following the next rule. We consider as ground truth the dominant LULC class, such LULC class occupies at least $70 \%$ of the pixel. The presence of up to $30 \%$ of features of other different LULC classes within the dominate class are ignored.

- Once the validated LULC classification matrix was obtained (Table 5), the F1 score was calculated at all the LULC levels (from L0 to L5), labeled as LULC-L5 in Fig. 1. As it can be noticed, as we go up from level L0 to L5 the obtained dataset accuracy increases from $87 \%$ to $96 \%$ due mainly to the forests classification.

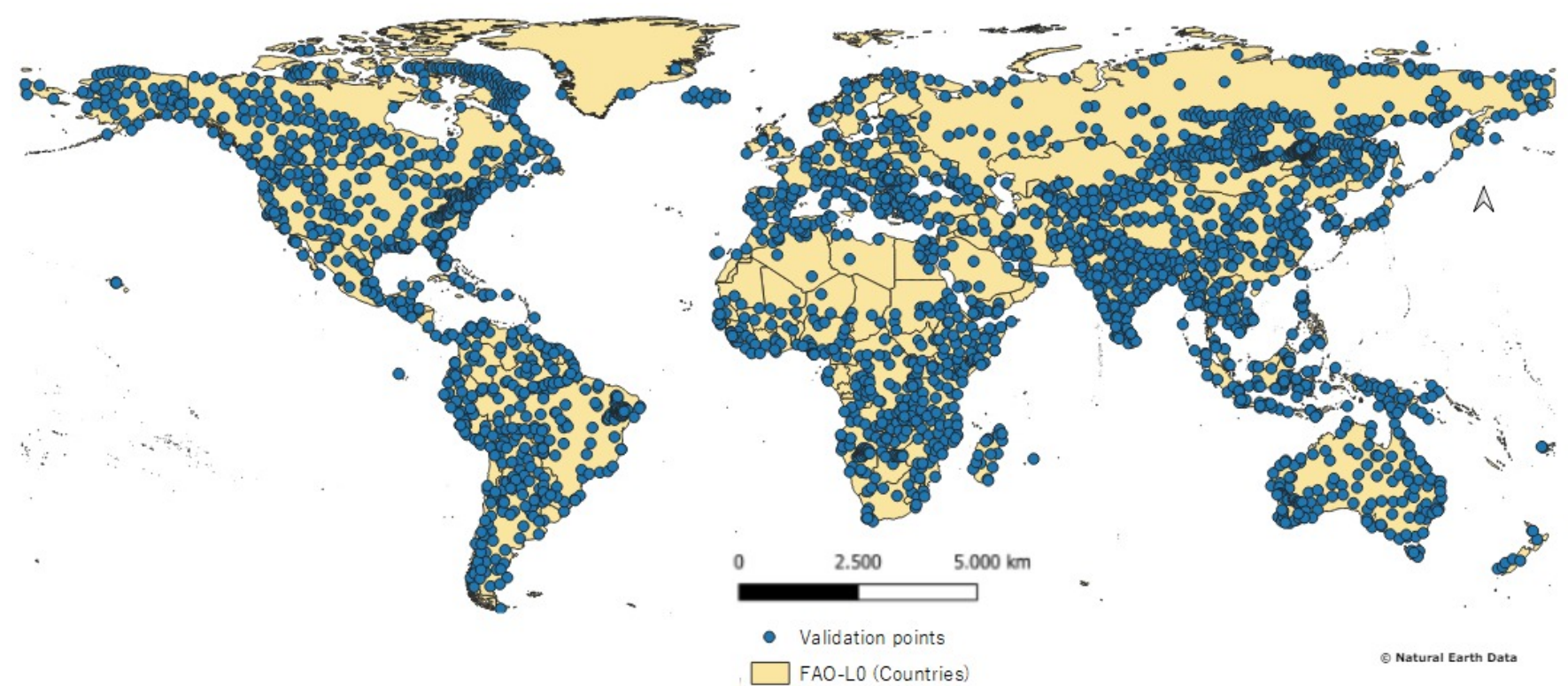

Figure 6. Global distribution of the selected 2,900 pixels to perform the quality control of the TimeSpec4LULC dataset for all the 29 LULC classes.

${ }^{3}$ https://www.bing.com/maps/ 
Table 5. Description of the data quality control results of the 2900 pixels for each LULC level (L0 to L5) using the F1 score. The correspondence between long and short names of the LULC-classes is provided in Table 6

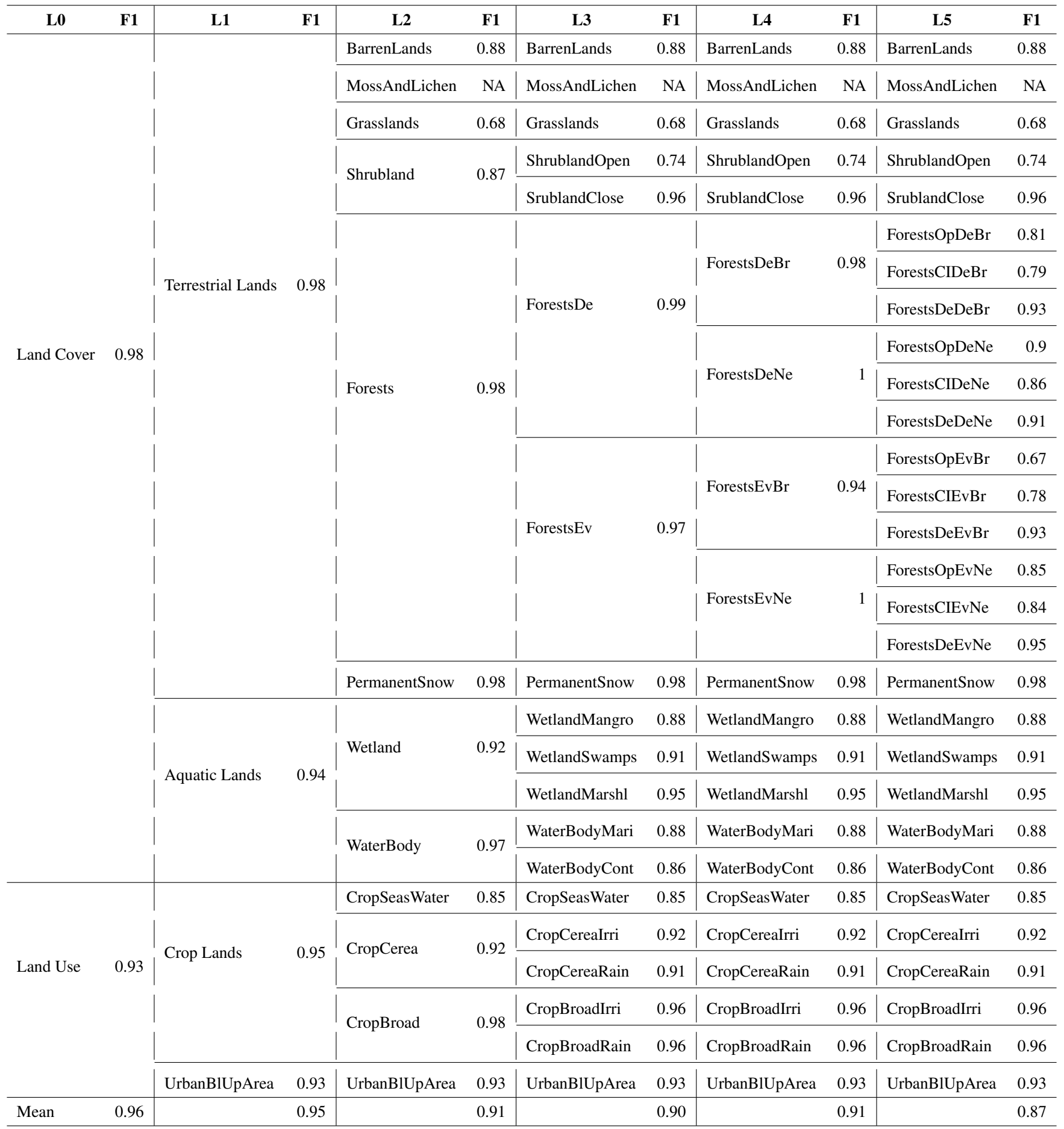




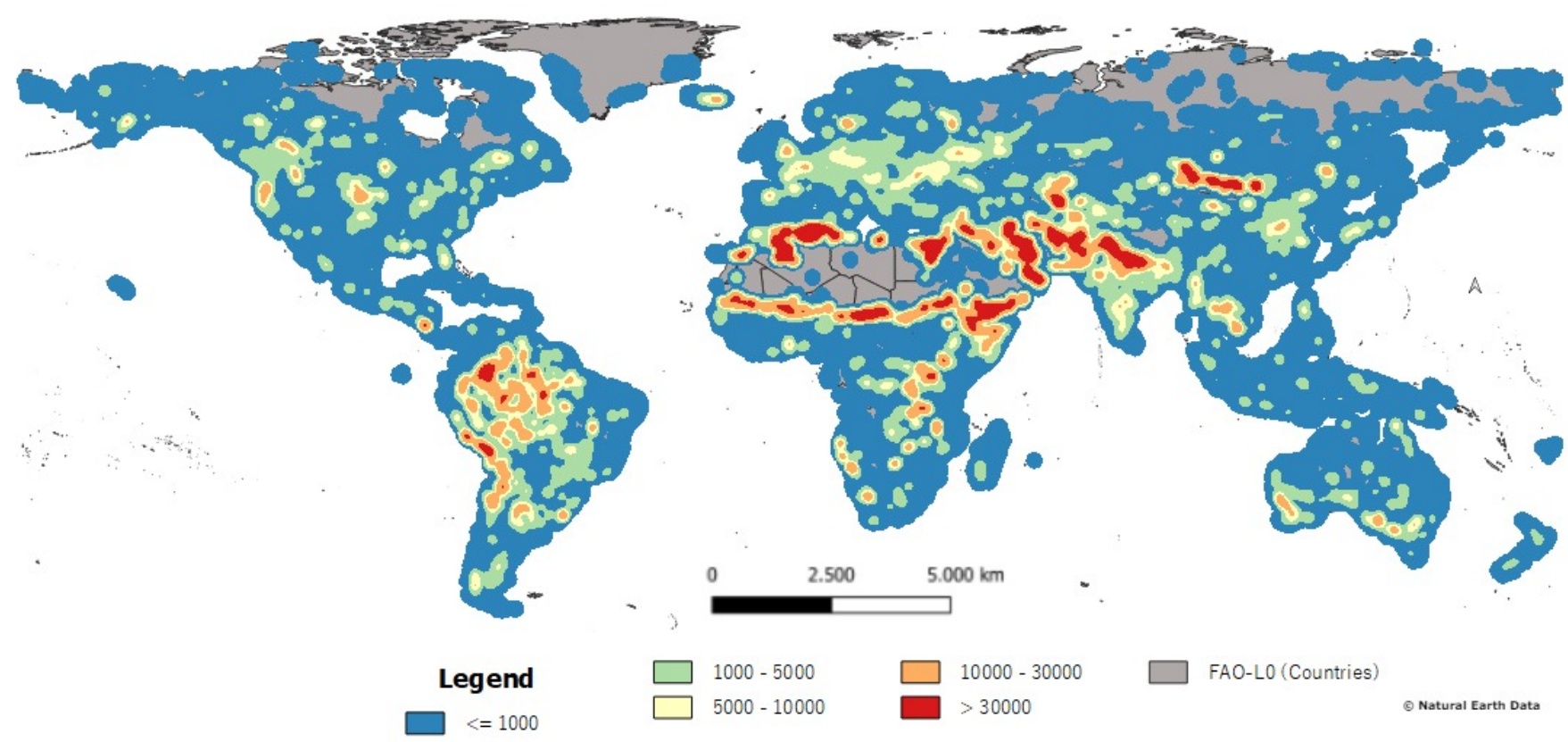

Figure 7. Global density of all the 11,856,992 collected pixels in the TimeSpec4LULC dataset for all the 29 LULC classes.

\section{Results and Discussion}

The total number of collected time series (pixels) in all the 29 LULC classes is $11,856,992$, which is large enough to build high quality DL models. The density of the collected pixels over the world is depicted by Fig. 7.

The number of collected time series, at the lowest purity, differs from one class to another according to the global abundance of each class (Table 6). But, in general, we have at least 1,158 time series in each LULC class which is sufficient for DL modeling. In 15 LULC classes, the number of collected time series, at purity $100 \%$, is at least 2,225 per class. This means that these classes have enough pure spectral information describing their behavior over time to train DL models with very high accuracy. However, in the remaining 14 LULC classes, the number of time series, collected at purity $100 \%$, is either small (with Close shrublands, Dense Evergreen Needleleaf Forests, and Marshland wetlands) or null in the remaining Wetlands classes and Forests classes (except Dense Broadleaf classes). This implies that, within $500 \mathrm{~m}$ pixels, the LULC products are less consistent within these classes and that it may exist remaining noise in one LULC class from other LULC classes. Since our dataset provides the level of spatial purity at pixel level, the user can always select the desired purity threshold.

Certain number of time series in each LULC class still contain some missing data that could be handled neither with the monthly aggregation process nor with the Terra-Aqua merging process (Table 7). The LULC classes that have less than 1000 time series (i.e., MODIS pixels) without missing data in at least one spectral band are Moss and Lichen lands, Close Shrublands, Open and Dense Deciduous Broadleaf Forests, all Deciduous Needleleaf Forests, Open Evergreen Broadleaf Forests, Mangrove wetlands, Swamp wetlands, Permanent snow, and Croplands flooded with seasonal water. This means that the multi-spectral 
https://doi.org/10.5194/essd-2021-253

Preprint. Discussion started: 12 October 2021

(c) Author(s) 2021. CC BY 4.0 License.

(c) (i)

time series information of these classes is hugely affected by atmospheric and/or land conditions. For almost all LULC classes

(except Barren Lands, Continental Water Bodies, and Rainfed Cereal Croplands), the number of time series without gaps is exactly the same over all the spectral bands excluding Band 6 which is the most contaminated by gaps. This severe drop in the number of time series without gaps in Band 6 compared to the other bands is due to the known "dead lines" in Aqua band 6 caused by the already reported malfunctioning or noise in some of its detectors (Zhang et al., 2018b).

Our dataset is distributed all over the world's FAO-L0 and FAO-L1 partitions (Fig. 8, Fig. 9, and Table 8). For almost all the 29 LULC classes, the collected time series covers more than 9 countries, except with Moss and Lichen lands, which were collected from 2 countries, and Deciduous Needleleaf Forests, which were collected from 3 countries. This small number of countries covered by these classes is due to their natural scarce distribution over the world. Contrary, some of the LULC classes, namely Water Bodies (Marine and Continental), Rainfed Croplands (Cereal and Broadleaf), and Urban and built-up areas have a broad world coverage, i.e., more than 80 countries and more than 570 departments (Fig. 8 and Fig. 9).

According to Fig. 10, the gHM index of the five cropland classes, and the Urban and built-up areas class is widely higher (more than 59\% of human change) compared to the other land cover classes, which proves their accurate annotation as human Land Uses.

This smartly, pre-processed, and annotated dataset is targeted towards scientific users interested in developing and evaluating various DL models to detect LULCs and monitor their change. For example, TimeSpec4LULC can be used i) to characterize the seasonal and inter-annual dynamics and changes of vegetation types and LULC classes, ii) to perform environmental monitoring, management and planning, ii) to study the intra-class behaviors of LULCs, i.e., assess the behavior of one specific LULC in different areas of the world and see whether it maintains the same pattern or it reveals different patterns, and iii) to study the inter-class differences and similarities of LULCs, i.e., recognise and compare the patterns and dynamics of all LULCs (e.g., time series segmentation).

\section{Conclusions}

Accurate LULC mapping and change detection is highly relevant for many applications, including Earth system modeling, environmental monitoring, management and planning, or natural hazards assessment, among many others. However, there still exists a high level of disagreement across current global LULC products, particularly for some LULC classes. To address the challenge of improving LULC products and change detection, we have created a smart open-source global dataset of multi-spectral time series for 29 LULC classes containing almost 11.85 million pixels annotated by using the spatio-temporal agreement across the 15 global LULC products available in GEE. The 29 LULC classes were hierarchically grouped into a legend with five levels. The monthly 7-band time series dataset was made by merging the two MODIS sensor data records, Terra and Aqua, at $500 \mathrm{~m}$ resolution and expands 19 years from 2002 to 2021. Each pixel is provided with a set of metadata about geographic coordinates, country and departmental divisions, spatio-temporal consistency across LULC products, temporal data availability, and the global human modification index. Finally, to assess the annotation quality of the dataset, a sample of 100 pixels per class, evenly distributed around the world, was selected by maximizing the distance among sampled 
https://doi.org/10.5194/essd-2021-253

Preprint. Discussion started: 12 October 2021

(c) Author(s) 2021. CC BY 4.0 License.

(c) (1)

pixels, and validated with photo-interpretation by experts using very high resolution images from both Google Earth and Bing Maps. The overall accuracy (F1 value) of the annotation varied from $96 \%$ at the coarser classification level to $87 \%$ at the finest level. This smartly, pre-processed, and annotated dataset is targeted towards scientific users interested in developing and evaluating various machine learning models, including deep learning networks, to perform global LULC mapping and change detection.

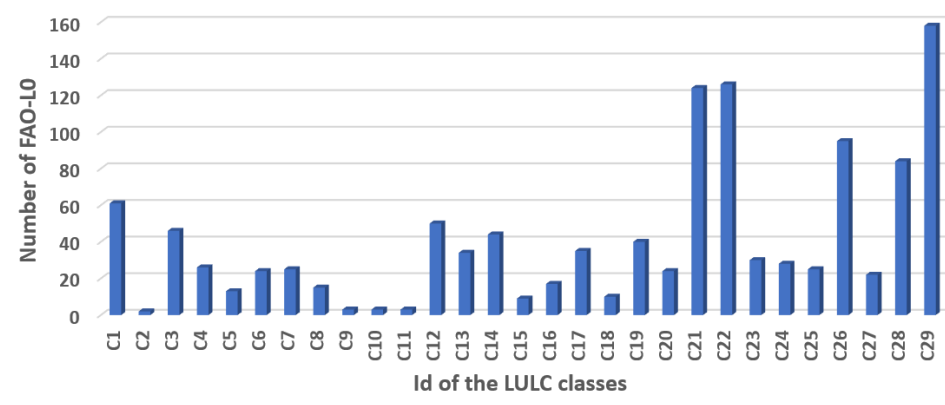

Figure 8. Distribution of the number of covered countries (FAO-L0) over the 29 LULC classes.

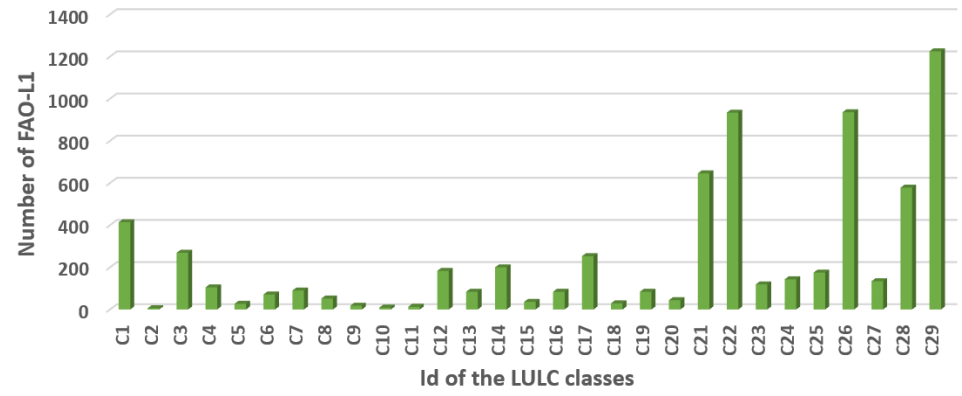

Figure 9. Distribution of the number of covered departments (FAO-L1) over the 29 LULC classes.

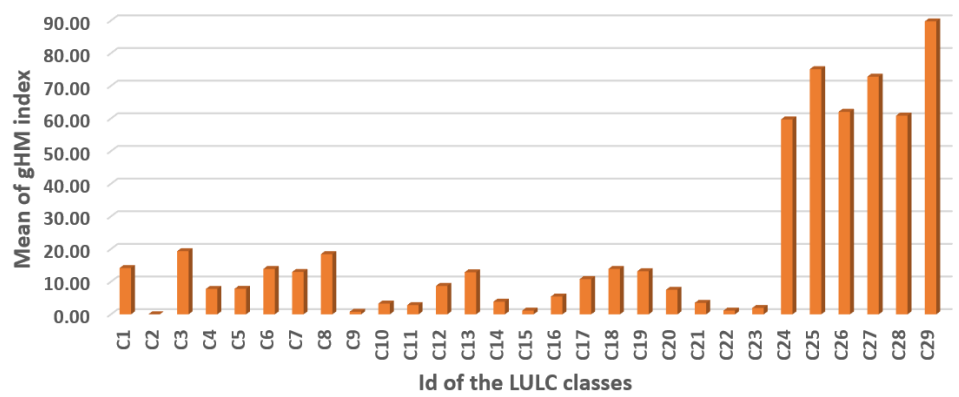

Figure 10. Distribution of the mean of the Global Human Modification (gHM) index over the 29 LULC classes. 
Table 6. Description of the full and short name of each LULC class along with the number of pixels collected at purity $100 \%$ and at the lowest purity retrieved.

\begin{tabular}{|c|c|c|c|c|c|}
\hline Class Id & LULC class full name & LULC class short name & $\begin{array}{l}\text { \# Pixels retrieved } \\
\text { at purity } 100 \%\end{array}$ & $\begin{array}{l}\text { Lowest purity } \\
\text { in the dataset }\end{array}$ & \# Collected pixels \\
\hline $\mathrm{C} 1$ & Barren lands & BarrenLands & $5,866,886$ & 1 & $5,866,886$ \\
\hline $\mathrm{C} 2$ & Moss and lichen lands & MossAndLichen & 2,804 & 1 & 2,804 \\
\hline $\mathrm{C} 3$ & Grasslands & Grasslands & 890,842 & 1 & 890,842 \\
\hline $\mathrm{C} 4$ & Open shrublands & ShrublandOpen & 121,273 & 1 & 121,273 \\
\hline $\mathrm{C} 5$ & Close shrublands & SrublandClose & 4 & 0.95 & 2,910 \\
\hline C6 & Open Deciduous Broadleaf Forests & ForestsOpDeBr & 0 & 0.85 & 6,956 \\
\hline $\mathrm{C} 7$ & Close Deciduous Broadleaf Forests & ForestsClDeBr & 0 & 0.85 & 35,445 \\
\hline $\mathrm{C} 8$ & Dense Deciduous Broadleaf Forests & ForestsDeDeBr & 2,225 & 1 & 2,225 \\
\hline C9 & Open Deciduous Needleleaf Forests & ForestsOpDeNe & 0 & 0.75 & 5,266 \\
\hline $\mathrm{C} 10$ & Close Deciduous Needleleaf Forests & ForestsClDeNe & 0 & 0.85 & 1,348 \\
\hline $\mathrm{C} 11$ & Dense Deciduous Needleleaf Forests & ForestsDeDeNe & 0 & 0.95 & 10,716 \\
\hline $\mathrm{C} 12$ & Open Evergreen Broadleaf Forests & ForestsOpEvBr & 0 & 0.75 & 22,315 \\
\hline $\mathrm{C} 13$ & Close Evergreen Broadleaf Forests & ForestsClEvBr & 0 & 0.85 & 3,245 \\
\hline $\mathrm{C} 14$ & Dense Evergreen Broadleaf Forests & ForestsDeEvBr & $1,198,448$ & 1 & $1,198,448$ \\
\hline $\mathrm{C} 15$ & Open Evergreen Needleleaf Forests & ForestsOpEvNe & 0 & 0.75 & 20,314 \\
\hline $\mathrm{C} 16$ & Close Evergreen Needleleaf Forests & ForestsClEvNe & 0 & 0.85 & 4,232 \\
\hline $\mathrm{C} 17$ & Dense Evergreen Needleleaf Forests & ForestsDeEvNe & 199 & 0.95 & 323,892 \\
\hline $\mathrm{C} 18$ & Mangrove wetlands & WetlandMangro & 0 & 0.85 & 4,707 \\
\hline C19 & Swamp wetlands & WetlandSwamps & 0 & 0.85 & 1,158 \\
\hline $\mathrm{C} 20$ & Marshland wetlands & WetlandMarshl & 80 & 0.85 & 9,303 \\
\hline $\mathrm{C} 21$ & Marine water bodies & WaterBodyMari & 107,467 & 1 & 107,467 \\
\hline $\mathrm{C} 22$ & Continental water bodies & WaterBodyCont & 977,759 & 1 & 977,759 \\
\hline $\mathrm{C} 23$ & Permanent snow & PermanentSnow & 99,798 & 1 & 99,798 \\
\hline $\mathrm{C} 24$ & Croplands flooded with seasonal water & CropSeasWater & 38,636 & 1 & 38,636 \\
\hline $\mathrm{C} 25$ & Irrigated cereal croplands & CropCereaIrri & 402,049 & 1 & 402,049 \\
\hline $\mathrm{C} 26$ & Rainfed cereal croplands & CropCereaRain & 786,837 & 1 & 786,837 \\
\hline $\mathrm{C} 27$ & Irrigated broadleaf croplands & CropBroadIrri & 392,091 & 1 & 392,091 \\
\hline $\mathrm{C} 28$ & Rainfed broadleaf croplands & CropBroadRain & 359,141 & 1 & 359,141 \\
\hline $\mathrm{C} 29$ & Urban and built-up areas & UrbanBIUpArea & 158,929 & 1 & 158,929 \\
\hline
\end{tabular}


Table 7. Description of the number of time series without missing data per spectral bands.

\begin{tabular}{rrrrrrrr}
\hline Class Id & Band 1 & Band 2 & Band 3 & Band 4 & Band 5 & Band 6 & Band 7 \\
\hline \hline C1 & $4,378,501$ & $4,378,501$ & $4,378,501$ & $4,378,473$ & $4,378,501$ & $3,947,731$ & $4,378,501$ \\
\hline C2 & 0 & 0 & 0 & 0 & 0 & 0 & 0 \\
\hline C3 & 414,963 & 414,963 & 414,963 & 414,963 & 414,963 & 310,326 & 414,963 \\
\hline C4 & 104,633 & 104,633 & 104,633 & 104,633 & 104,633 & 90,892 & 104,633 \\
\hline C5 & 1,099 & 1,099 & 1,099 & 1,099 & 1,099 & 886 & 1,099 \\
\hline C6 & 1,035 & 1,035 & 1,035 & 1,035 & 1,035 & 559 & 1,035 \\
\hline C7 & 7,675 & 7,675 & 7,675 & 7,675 & 7,675 & 5,463 & 7,675 \\
\hline C8 & 110 & 110 & 110 & 110 & 110 & 25 & 110 \\
\hline C9 & 11 & 11 & 11 & 11 & 11 & 1 & 11 \\
\hline C10 & 0 & 0 & 0 & 0 & 0 & 0 & 0 \\
\hline C11 & 0 & 0 & 0 & 0 & 0 & 0 & 0 \\
\hline C12 & 1,024 & 1,024 & 1,024 & 1,024 & 1,024 & 552 & 1,024 \\
\hline C13 & 1,957 & 1,957 & 1,957 & 1,957 & 1,957 & 1,498 & 1,957 \\
\hline C14 & 8,488 & 8,488 & 8,488 & 8,488 & 8,488 & 3,610 & 8,488 \\
\hline C15 & 1,740 & 1,740 & 1,740 & 1,740 & 1,740 & 1,574 & 1,740 \\
\hline C16 & 1,386 & 1,386 & 1,386 & 1,386 & 1,386 & 1,068 & 1,386 \\
\hline C17 & 22,488 & 22,488 & 22,488 & 22,488 & 22,488 & 8,219 & 22,488 \\
\hline C18 & 690 & 690 & 690 & 690 & 690 & 201 & 690 \\
\hline C19 & 287 & 287 & 287 & 287 & 287 & 257 & 287 \\
\hline C20 & 1,409 & 1,409 & 1,409 & 1,409 & 1,409 & 1,134 & 1,409 \\
\hline C21 & 11,640 & 11,640 & 11,640 & 11,640 & 11,640 & 1,151 & 11,640 \\
\hline C22 & 140,856 & 140,854 & 140,856 & 140,856 & 140,856 & 44,302 & 140,856 \\
\hline C23 & 138 & 138 & 138 & 138 & 138 & 11 & 138 \\
\hline C24 & 269 & 269 & 269 & 269 & 269 & 96 & 269 \\
\hline C25 & 25,142 & 25,142 & 25,142 & 25,142 & 25,142 & 17,607 & 25,142 \\
\hline C26 & 262,632 & 262,630 & 262,630 & 262,630 & 262,630 & 181,382 & 262,630 \\
\hline C27 & 29,154 & 29,154 & 29,154 & 29,154 & 29,154 & 14,636 & 29,154 \\
\hline C28 & 79,686 & 79,686 & 79,686 & 79,686 & 79,686 & 43,080 & 79,686 \\
\hline C29 & 20,289 & 20,289 & 20,289 & 20,289 & 20,289 & 10,697 & 20,289 \\
\hline
\end{tabular}


Table 8: Description of the number of FAO-L0 and FAO-L1 covered by the collected pixels along with the mean and (the standard deviation) of the pixels gHM index, purity, and temporal availability percentage over the seven spectral bands.

\begin{tabular}{|c|c|c|c|c|c|c|c|c|c|c|c|}
\hline \multirow{2}{*}{ Class Id } & \multirow{2}{*}{$\begin{array}{c}\text { \# FAO } \\
\text { LO }\end{array}$} & \multirow{2}{*}{$\begin{array}{c}\text { \# FAO } \\
\text { L1 }\end{array}$} & \multirow{2}{*}{$\begin{array}{l}\text { gHM } \\
\text { index }\end{array}$} & \multirow{2}{*}{$\begin{array}{c}\text { Purity } \\
(\%)\end{array}$} & \multicolumn{7}{|c|}{ Temporal Availability Percentage (\%) } \\
\hline & & & & & Band 1 & Band 2 & Band 3 & Band 4 & Band 5 & Band 6 & Band 7 \\
\hline \multirow[t]{2}{*}{$\mathrm{C} 1$} & 61 & 414 & 14.19 & 100 & 98.51 & 98.50 & 98.50 & 98.50 & 98.50 & 98.07 & 98.50 \\
\hline & & & $(10.20)$ & $(0.00)$ & (8.10) & $(8.14)$ & $(8.14)$ & $(8.14)$ & $(8.14)$ & (8.74) & $(8.14)$ \\
\hline \multirow[t]{2}{*}{$\mathrm{C} 2$} & 2 & 6 & 0.01 & 100 & 51.24 & 51.24 & 51.24 & 51.24 & 51.24 & 46.69 & 51.24 \\
\hline & & & $(0.23)$ & $(0.00)$ & $(17.85)$ & $(17.85)$ & $(17.85)$ & $(17.85)$ & $(17.85)$ & (17.54) & $(17.85)$ \\
\hline \multirow[t]{2}{*}{ C3 } & 46 & 269 & 19.35 & 100 & 98.26 & 98.26 & 98.26 & 98.26 & 98.26 & 97.72 & 98.26 \\
\hline & & & (14.09) & $(0.00)$ & (6.77) & (6.77) & $(6.77)$ & (6.77) & $(6.77)$ & (7.38) & $(6.77)$ \\
\hline \multirow[t]{2}{*}{$\mathrm{C} 4$} & 26 & 105 & 7.79 & 100 & 99.64 & 99.64 & 99.64 & 99.64 & 99.64 & 99.44 & 99.64 \\
\hline & & & $(8.82)$ & $(0.00)$ & $(4.31)$ & $(4.31)$ & $(4.31)$ & $(4.31)$ & $(4.31)$ & $(4.61)$ & $(4.31)$ \\
\hline \multirow[t]{2}{*}{ C5 } & 13 & 27 & 7.83 & 96.78 & 98.85 & 98.85 & 98.85 & 98.85 & 98.85 & 97.85 & 98.85 \\
\hline & & & $(5.82)$ & $(1.32)$ & $(2.85)$ & $(2.85)$ & $(2.85)$ & $(2.85)$ & $(2.85)$ & $(3.65)$ & (2.85) \\
\hline \multirow[t]{2}{*}{ C6 } & 24 & 71 & 13.91 & 85.78 & 98.21 & 98.21 & 98.21 & 98.21 & 98.21 & 97.11 & 98.21 \\
\hline & & & $(6.41)$ & $(0.68)$ & $(2.83)$ & $(2.83)$ & $(2.83)$ & (2.83) & $(2.83)$ & $(3.40)$ & (2.83) \\
\hline \multirow[t]{2}{*}{ C7 } & 25 & 90 & 12.99 & 86.09 & 97.53 & 97.53 & 97.53 & 97.53 & 97.53 & 95.96 & 97.53 \\
\hline & & & $(5.58)$ & (1.07) & $(3.52)$ & $(3.52)$ & $(3.52)$ & $(3.52)$ & $(3.52)$ & $(4.62)$ & (3.52) \\
\hline \multirow[t]{2}{*}{ C8 } & 15 & 52 & 18.44 & 100 & 90.18 & 90.18 & 90.18 & 90.18 & 90.18 & 88.12 & 90.18 \\
\hline & & & $(9.86)$ & $(0.00)$ & (11.65) & (11.65) & $(11.65)$ & $(11.65)$ & (11.65) & (12.69) & (11.65) \\
\hline \multirow[t]{2}{*}{ C9 } & 3 & 18 & 0.79 & 76.37 & 89.29 & 89.29 & 89.29 & 89.29 & 89.29 & 88.05 & 89.29 \\
\hline & & & (2.39) & (1.29) & $(8.47)$ & $(8.47)$ & $(8.47)$ & $(8.47)$ & $(8.47)$ & $(8.83)$ & (8.47) \\
\hline \multirow[t]{2}{*}{$\mathrm{C} 10$} & 3 & 9 & 3.31 & 85.51 & 78.51 & 78.51 & 78.51 & 78.51 & 78.51 & 76.07 & 78.51 \\
\hline & & & (3.73) & $(0.43)$ & $(7.87)$ & (7.87) & (7.87) & $(7.87)$ & $(7.87)$ & $(8.00)$ & (7.87) \\
\hline \multirow[t]{2}{*}{ C11 } & 3 & 13 & 2.83 & 96.10 & 85.79 & 85.79 & 85.79 & 85.79 & 85.79 & 82.69 & 85.79 \\
\hline & & & (3.77) & $(0.92)$ & $(9.20)$ & $(9.20)$ & $(9.20)$ & $(9.20)$ & $(9.20)$ & (9.64) & $(9.20)$ \\
\hline \multirow[t]{2}{*}{$\mathrm{C} 12$} & 50 & 183 & 8.71 & 77.27 & 84.65 & 84.65 & 84.65 & 84.65 & 84.65 & 79.97 & 84.65 \\
\hline & & & (14.26) & (2.07) & $(18.30)$ & $(18.30)$ & (18.30) & $(18.30)$ & $(18.30)$ & (19.28) & $(18.30)$ \\
\hline \multirow[t]{2}{*}{ C13 } & 34 & 84 & 12.89 & 86.46 & 90.67 & 90.67 & 90.67 & 90.67 & 88.50 & 85.85 & 90.67 \\
\hline & & & (12.06) & (1.44) & (20.30) & (20.30) & (20.30) & (20.30) & (20.30) & (21.68) & $(20.30)$ \\
\hline $\mathrm{C} 14$ & 44 & 200 & 3.88 & 100 & 88.86 & 88.87 & 88.87 & 88.87 & 88.87 & 82.95 & 88.87 \\
\hline
\end{tabular}


Table 8: - Continued from previous page

\begin{tabular}{|c|c|c|c|c|c|c|c|c|c|c|c|}
\hline \multirow[t]{2}{*}{ Class Id } & \multirow{2}{*}{$\begin{array}{c}\text { \# FAO } \\
\text { LO }\end{array}$} & \multirow{2}{*}{$\begin{array}{c}\text { \# FAO } \\
\text { L1 }\end{array}$} & \multirow{2}{*}{$\begin{array}{l}\text { gHM } \\
\text { index }\end{array}$} & \multirow{2}{*}{$\begin{array}{c}\text { Purity } \\
(\%)\end{array}$} & \multicolumn{7}{|c|}{ Temporal Availability (\%) } \\
\hline & & & & & Band 1 & Band 2 & Band 3 & Band 4 & Band 5 & Band 6 & Band 7 \\
\hline & & & $(4.04)$ & $(0.00)$ & (9.17) & $(9.10)$ & $(9.10)$ & $(9.10)$ & $(9.10)$ & $(9.93)$ & (9.10) \\
\hline \multirow[t]{2}{*}{ C15 } & 9 & 36 & 1.15 & 76.54 & 59.21 & 59.21 & 59.21 & 59.21 & 59.21 & 56.90 & 59.21 \\
\hline & & & (3.30) & $(1.31)$ & $(37.87)$ & $(37.87)$ & (37.87) & $(37.87)$ & (37.87) & (37.74) & (37.87) \\
\hline \multirow[t]{2}{*}{ C16 } & 17 & 84 & 5.46 & 86.13 & 88.61 & 88.61 & 88.61 & 88.61 & 88.61 & 86.55 & 88.61 \\
\hline & & & $(6.47)$ & (1.03) & $(24.75)$ & $(24.75)$ & $(24.75)$ & $(24.75)$ & (24.75) & (25.84) & $(24.75)$ \\
\hline \multirow[t]{2}{*}{ C17 } & 35 & 253 & 10.81 & 85.40 & 85.40 & 85.40 & 85.40 & 85.40 & 85.40 & 82.27 & 85.40 \\
\hline & & & $(13.92)$ & $(1.41)$ & $(26.61)$ & $(26.61)$ & $(26.61)$ & $(26.61)$ & $(26.62)$ & $(27.26)$ & $(26.61)$ \\
\hline \multirow[t]{2}{*}{$\mathrm{C} 18$} & 10 & 29 & 13.92 & 87.58 & 97.93 & 97.93 & 97.93 & 97.93 & 97.93 & 95.82 & 97.93 \\
\hline & & & $(9.70)$ & $(2.38)$ & (4.14) & (4.14) & $(4.14)$ & $(4.14)$ & (4.14) & $(5.98)$ & (4.14) \\
\hline \multirow[t]{2}{*}{ C19 } & 40 & 84 & 13.20 & 87.08 & 95.58 & 95.58 & 95.58 & 95.58 & 95.58 & 92.65 & 95.58 \\
\hline & & & $(9.92)$ & $(2.16)$ & $(7.01)$ & (7.01) & (7.01) & (7.01) & (7.01) & $(9.57)$ & (7.01) \\
\hline \multirow[t]{2}{*}{ C20 } & 24 & 44 & 7.52 & 90.43 & 74.97 & 74.97 & 74.97 & 74.97 & 74.97 & 71.57 & 74.97 \\
\hline & & & $(11.96)$ & $(3.86)$ & (17.53) & $(17.53)$ & $(17.53)$ & $(17.53)$ & (17.53) & (18.45) & $(17.53)$ \\
\hline \multirow[t]{2}{*}{$\mathrm{C} 21$} & 124 & 646 & 3.50 & 100 & 90.98 & 90.98 & 90.96 & 90.98 & 90.98 & 84.29 & 90.98 \\
\hline & & & (11.10) & $(0.00)$ & (11.43) & (11.44) & (11.52) & $(11.43)$ & (11.43) & $(14.40)$ & (11.43) \\
\hline \multirow[t]{2}{*}{ C22 } & 126 & 934 & 1.15 & 100 & 87.98 & 87.98 & 87.96 & 87.98 & 87.98 & 81.46 & 87.98 \\
\hline & & & $(6.02)$ & $(0.00)$ & (13.29) & (13.30) & (12.67) & (13.29) & (13.29) & (16.54) & (13.29) \\
\hline \multirow[t]{2}{*}{$\mathrm{C} 23$} & 30 & 119 & 1.96 & 100 & 78.50 & 78.50 & 78.50 & 78.50 & 78.50 & 72.06 & 78.50 \\
\hline & & & $(5.63)$ & $(0.00)$ & (11.52) & (11.52) & (11.52) & (11.52) & (11.52) & (12.85) & (11.52) \\
\hline \multirow[t]{2}{*}{$\mathrm{C} 24$} & 28 & 143 & 59.72 & 100 & 79.60 & 79.60 & 79.60 & 79.60 & 79.60 & 74.86 & 79.60 \\
\hline & & & (18.78) & $(0.00)$ & $(9.45)$ & $(9.45)$ & $(9.45)$ & $(9.45)$ & $(9.45)$ & (9.84) & (9.45) \\
\hline \multirow[t]{2}{*}{$\mathrm{C} 25$} & 25 & 175 & 75.11 & 100 & 92.13 & 92.13 & 92.13 & 92.13 & 92.13 & 89.93 & 92.13 \\
\hline & & & (6.07) & $(0.00)$ & $(9.80)$ & $(9.80)$ & $(9.80)$ & $(9.80)$ & $(9.80)$ & (10.67) & $(9.80)$ \\
\hline \multirow[t]{2}{*}{$\mathrm{C} 26$} & 95 & 936 & 62.05 & 100 & 95.43 & 95.43 & 95.43 & 95.43 & 95.43 & 94.02 & 95.43 \\
\hline & & & $(13.42)$ & $(0.00)$ & (10.47) & (10.47) & (10.47) & (10.47) & (10.47) & (11.50) & (10.47) \\
\hline \multirow[t]{2}{*}{$\mathrm{C} 27$} & 22 & 134 & 72.82 & 100 & 88.47 & 88.47 & 88.47 & 88.47 & 88.47 & 85.97 & 88.47 \\
\hline & & & $(7.21)$ & $(0.00)$ & (9.63) & $(9.63)$ & (9.63) & (9.63) & $(9.63)$ & (10.73) & (9.63) \\
\hline $\mathrm{C} 28$ & 84 & 578 & 60.89 & 100 & 95.00 & 95.00 & 95.00 & 95.00 & 95.00 & 93.50 & 95.00 \\
\hline
\end{tabular}


https://doi.org/10.5194/essd-2021-253

Preprint. Discussion started: 12 October 2021

(c) Author(s) 2021. CC BY 4.0 License.

(c) (1)

Table 8: - Continued from previous page

\begin{tabular}{|c|c|c|c|c|c|c|c|c|c|c|c|}
\hline \multirow[t]{2}{*}{ Class Id } & \multirow{2}{*}{$\begin{array}{c}\text { \# FAO } \\
\text { LO }\end{array}$} & \multirow{2}{*}{$\begin{array}{c}\text { \# FAO } \\
\text { L1 }\end{array}$} & \multirow{2}{*}{$\begin{array}{l}\text { gHM } \\
\text { index }\end{array}$} & \multirow{2}{*}{$\begin{array}{c}\text { Purity } \\
(\%)\end{array}$} & \multicolumn{7}{|c|}{ Temporal Availability (\%) } \\
\hline & & & & & Band 1 & Band 2 & Band 3 & Band 4 & Band 5 & Band 6 & Band 7 \\
\hline & & & $(12.60)$ & $(0.00)$ & $(9.46)$ & $(9.46)$ & $(9.46)$ & $(9.46)$ & $(9.46)$ & (10.55) & $(9.46)$ \\
\hline \multirow[t]{2}{*}{ C29 } & 158 & 1225 & 89.75 & 100 & 80.99 & 80.99 & 80.99 & 80.99 & 80.99 & 77.26 & 80.99 \\
\hline & & & $(5.30)$ & $(0.00)$ & (28.39) & $(28.39)$ & (28.39) & (28.39) & (28.39) & $(29.25)$ & (28.39) \\
\hline
\end{tabular}

Code and data availability. This dataset (Khaldi et al., 2021) is available to the public through an unrestricted data repository hosted by Zenodo at https://zenodo.org/record/5020024\#.YWARotpBxaQ.

Author contributions. RK contributed to the conception of the dataset, implemented the code, performed all the data extraction and wrote the paper. DA-S contributed to the conception of the dataset, assessed its quality, provided guidance, and wrote the paper. EG assessed the quality of the dataset. YB contributed to the conception of the dataset. AE and FH provided edits and suggestions. ST contributed to the conception of the dataset, provided guidance, and wrote the paper.

Competing interests. The authors declare that they have no conflict of interest.

Acknowledgements. This work was partially supported by DETECTOR (A-RNM-256-UGR18 Universidad de Granada/FEDER), LifeWatch SmartEcomountains (LifeWatch-2019-10-UGR-01 Ministerio de Ciencia e Innovación/Universidad de Granada/FEDER), BBVA DeepSCOP (Ayudas Fundación BBVA a Equipos de Investigación Científica 2018), DeepL-ISCO (A-TIC-458-UGR18 Ministerio de Ciencia e Innovación/FEDER), SMART-DASCI (TIN2017-89517-P Ministerio de Ciencia e Innovación/Universidad de Granada/FEDER), BigDDL-CET (P18-FR-4961 Ministerio de Ciencia e Innovación/Universidad de Granada/FEDER), RESISTE (P18-RT-1927 Consejería de Economía, Conocimiento, y Universidad from the Junta de Andalucía/FEDER), and Ecopotential (641762 European Commission). S. Tabik was supported by the Ramón y Cajal Programme (RYC-2015-18136). 
https://doi.org/10.5194/essd-2021-253

Preprint. Discussion started: 12 October 2021

(c) Author(s) 2021. CC BY 4.0 License.

(c) (i)

\section{References}

Alexakis, D., Grillakis, M., Koutroulis, A. G., Agapiou, A., Themistocleous, K., Tsanis, I., Michaelides, S., Pashiardis, S., Demetriou, C., Aristeidou, K., et al.: GIS and remote sensing techniques for the assessment of land use change impact on flood hydrology: the case study of Yialias basin in Cyprus, Natural Hazards and Earth System Sciences, 14, 413-426, 2014.

Bartholome, E. and Belward, A. S.: GLC2000: a new approach to global land cover mapping from Earth observation data, International Journal of Remote Sensing, 26, 1959-1977, 2005.

Congalton, R. G., Gu, J., Yadav, K., Thenkabail, P., and Ozdogan, M.: Global land cover mapping: A review and uncertainty analysis, Remote Sensing, 6, 12 070-12 093, 2014.

de la Cruz, M., Quintana-Ascencio, P. F., Cayuela, L., Espinosa, C. I., and Escudero, A.: Comment on "The extent of forest in dryland biomes", Science, 358, 2017.

Estes, L., Chen, P., Debats, S., Evans, T., Ferreira, S., Kuemmerle, T., Ragazzo, G., Sheffield, J., Wolf, A., Wood, E., et al.: A large-area, spatially continuous assessment of land cover map error and its impact on downstream analyses, Global change biology, 24, 322-337, 2018.

Feddema, J. J., Oleson, K. W., Bonan, G. B., Mearns, L. O., Buja, L. E., Meehl, G. A., and Washington, W. M.: The importance of land-cover change in simulating future climates, Science, 310, 1674-1678, 2005.

Feng, M. and Bai, Y.: A global land cover map produced through integrating multi-source datasets, Big Earth Data, 3, $191-219,2019$.

Fritz, S., You, L., Bun, A., See, L., McCallum, I., Schill, C., Perger, C., Liu, J., Hansen, M., and Obersteiner, M.: Cropland for sub-Saharan Africa: A synergistic approach using five land cover data sets, Geophysical Research Letters, 38, 2011.

Gao, Y., Liu, L., Zhang, X., Chen, X., Mi, J., and Xie, S.: Consistency Analysis and Accuracy Assessment of Three Global 30-m Land-Cover Products over the European Union using the LUCAS Dataset, Remote Sensing, 12, 3479, 2020.

García-Mora, T. J., Mas, J.-F., and Hinkley, E. A.: Land cover mapping applications with MODIS: a literature review, International Journal of Digital Earth, 5, 63-87, 2012.

Gengler, S. and Bogaert, P.: Combining land cover products using a minimum divergence and a Bayesian data fusion approach, International Journal of Geographical Information Science, 32, 806-826, 2018.

Gómez, C., White, J. C., and Wulder, M. A.: Optical remotely sensed time series data for land cover classification: A review, ISPRS Journal of Photogrammetry and Remote Sensing, 116, 55-72, 2016.

Gong, P., Wang, J., Yu, L., Zhao, Y., Zhao, Y., Liang, L., Niu, Z., Huang, X., Fu, H., Liu, S., et al.: Finer resolution observation and monitoring of global land cover: First mapping results with Landsat TM and ETM+ data, International Journal of Remote Sensing, 34, 2607-2654, 2013.

Gorelick, N., Hancher, M., Dixon, M., Ilyushchenko, S., Thau, D., and Moore, R.: Google Earth Engine: Planetary-scale geospatial analysis for everyone, Remote Sensing of Environment, https://doi.org/10.1016/j.rse.2017.06.031, 2017.

Grekousis, G., Mountrakis, G., and Kavouras, M.: An overview of 21 global and 43 regional land-cover mapping products, International Journal of Remote Sensing, 36, 5309-5335, 2015.

Guirado, E., Tabik, S., Alcaraz-Segura, D., Cabello, J., and Herrera, F.: Deep-learning versus OBIA for scattered shrub detection with Google earth imagery: Ziziphus Lotus as case study, Remote Sensing, 9, 1220, 2017. 
https://doi.org/10.5194/essd-2021-253

Preprint. Discussion started: 12 October 2021

(c) Author(s) 2021. CC BY 4.0 License.

(c) (i)

Guirado, E., Blanco-Sacristán, J., Rodríguez-Caballero, E., Tabik, S., Alcaraz-Segura, D., Martínez-Valderrama, J., and Cabello, J.: Mask R-CNN and OBIA Fusion Improves the Segmentation of Scattered Vegetation in Very High-Resolution Optical Sensors, Sensors, 21, 320, 2021.

Hoskins, A. J., Bush, A., Gilmore, J., Harwood, T., Hudson, L. N., Ware, C., Williams, K. J., and Ferrier, S.: Downscaling land-use data to provide global 30 "estimates of five land-use classes, Ecology and Evolution, 6, 3040-3055, 2016.

Hubert-Moy, L., Thibault, J., Fabre, E., Rozo, C., Arvor, D., Corpetti, T., and Rapinel, S.: Time-series spectral dataset for croplands in France (2006-2017), Data in Brief, 27, 104 810, https://doi.org/https://doi.org/10.1016/j.dib.2019.104810, 2019.

Jung, M., Henkel, K., Herold, M., and Churkina, G.: Exploiting synergies of global land cover products for carbon cycle modeling, Remote Sensing of Environment, 101, 534-553, 2006.

Kennedy, C. M., Oakleaf, J. R., Theobald, D. M., Baruch-Mordo, S., and Kiesecker, J.: Managing the middle: A shift in conservation priorities based on the global human modification gradient, Global Change Biology, 25, 811-826, 2019.

Kerr, J. T. and Ostrovsky, M.: From space to species: ecological applications for remote sensing, Trends in ecology \& evolution, 18, 299-305, 2003.

Khaldi, R., Alcaraz-Segura, D., Guirado, E., Benhammou, Y., and Tabik, S.: TimeSpec4LULC: A deep learning-oriented global dataset of MODIS Terra-Aqua multi-spectral time series measured from 2002 to 2021 for LULC mapping and change detection., https://doi.org/10.5281/zenodo.5020024, this research has been supported by DETECTOR (A-RNM-256-UGR18 Universidad de Granada/FEDER), LifeWatch SmartEcomountains (LifeWatch-2019-10-UGR-01 Ministerio de Ciencia e Innovación/Universidad de Granada/FEDER), BBVA DeepSCOP (Ayudas Fundación BBVA a Equipos de Investigación Científica 2018), Ramón y Cajal Programme (RYC-2015-18136), DeepL-ISCO (A-TIC-458-UGR18 Ministerio de Ciencia e Innovación/FEDER), SMART-DASCI (TIN2017-89517P Ministerio de Ciencia e Innovación/Universidad de Granada/FEDER), BigDDL-CET (P18-FR-4961 Ministerio de Ciencia e Innovación/Universidad de Granada/FEDER), RESISTE (P18-RT-1927 Consejería de Economía, Conocimiento, y Universidad from the Junta de Andalucía/FEDER), and Ecopotential (641762 European Commission)., 2021.

Kong, F., Li, X., Wang, H., Xie, D., Li, X., and Bai, Y.: Land cover classification based on fused data from GF-1 and MODIS NDVI time series, Remote Sensing, 8, 741, 2016.

Lambin, E. F. and Geist, H. J.: Land-use and land-cover change: local processes and global impacts, Springer Science \& Business Media, 2008.

Liu, L., Zhang, X., Gao, Y., Chen, X., Shuai, X., and Mi, J.: Finer-Resolution Mapping of Global Land Cover: Recent Developments, Consistency Analysis, and Prospects, Journal of Remote Sensing, 2021, 2021.

Loveland, T. R., Reed, B. C., Brown, J. F., Ohlen, D. O., Zhu, Z., Yang, L., and Merchant, J. W.: Development of a global land cover characteristics database and IGBP DISCover from 1 km AVHRR data, International Journal of Remote Sensing, 21, 1303-1330, 2000.

Luengo, J., García-Gil, D., Ramírez-Gallego, S., García, S., and Herrera, F.: Big data preprocessing - Enabling Smart Data, Cham: Springer, 2020.

Luoto, M., Virkkala, R., and Heikkinen, R. K.: The role of land cover in bioclimatic models depends on spatial resolution, Global ecology and biogeography, 16, 34-42, 2007.

Menke, S., Holway, D., Fisher, R., and Jetz, W.: Characterizing and predicting species distributions across environments and scales: Argentine ant occurrences in the eye of the beholder, Global Ecology and Biogeography, 18, 50-63, 2009.

Meyer, W. B., Meyer, W. B., BL Turner, I., et al.: Changes in land use and land cover: a global perspective, vol. 4, Cambridge University Press, 1994. 
https://doi.org/10.5194/essd-2021-253

Preprint. Discussion started: 12 October 2021

(c) Author(s) 2021. CC BY 4.0 License.

(c) (i)

Patel, S. K., Verma, P., and Singh, G. S.: Agricultural growth and land use land cover change in peri-urban India, Environmental monitoring and assessment, 191, 1-17, 2019.

Pérez-Hoyos, A., García-Haro, F. J., and San-Miguel-Ayanz, J.: A methodology to generate a synergetic land-cover map by fusion of different land-cover products, International Journal of Applied Earth Observation and Geoinformation, 19, 72-87, 2012.

Pfeifer, M., Disney, M., Quaife, T., and Marchant, R.: Terrestrial ecosystems from space: a review of earth observation products for macroecology applications, Global Ecology and Biogeography, 21, 603-624, 2012.

Polykretis, C., Grillakis, M. G., and Alexakis, D. D.: Exploring the impact of various spectral indices on land cover change detection using change vector analysis: A case study of Crete Island, Greece, Remote Sensing, 12, 319, 2020.

Rußwurm, M., Pelletier, C., Zollner, M., Lefèvre, S., and Körner, M.: BreizhCrops: A Time Series Dataset for Crop Type Mapping, arXiv preprint arXiv:1905.11893, 2019.

Safonova, A., Guirado, E., Maglinets, Y., Alcaraz-Segura, D., and Tabik, S.: Olive Tree Biovolume from UAV Multi-Resolution Image Segmentation with Mask R-CNN, Sensors, 21, 1617, 2021.

Townshend, J., Justice, C., Li, W., Gurney, C., and McManus, J.: Global land cover classification by remote sensing: present capabilities and future possibilities, Remote Sensing of Environment, 35, 243-255, 1991.

Tsendbazar, N., De Bruin, S., and Herold, M.: Assessing global land cover reference datasets for different user communities, ISPRS Journal of Photogrammetry and Remote Sensing, 103, 93-114, 2015a.

405 Tsendbazar, N.-E., De Bruin, S., Fritz, S., and Herold, M.: Spatial accuracy assessment and integration of global land cover datasets, Remote Sensing, 7, $15804-15821,2015 b$.

Tsendbazar, N.-E., de Bruin, S., Mora, B., Schouten, L., and Herold, M.: Comparative assessment of thematic accuracy of GLC maps for specific applications using existing reference data, International Journal of Applied Earth Observation and Geoinformation, 44, 124-135, 2016.

410 Tuanmu, M.-N. and Jetz, W.: A global 1-km consensus land-cover product for biodiversity and ecosystem modelling, Global Ecology and Biogeography, 23, 1031-1045, 2014.

Van Etten, A., Hogan, D., Martinez-Manso, J., Shermeyer, J., Weir, N., and Lewis, R.: The Multi-Temporal Urban Development SpaceNet Dataset, arXiv preprint arXiv:2102.04420, 2021.

Vancutsem, C., Marinho, E., Kayitakire, F., See, L., and Fritz, S.: Harmonizing and combining existing land cover/land use datasets for cropland area monitoring at the African continental scale, Remote Sensing, 5, 19-41, 2013.

Verburg, P. H., Van De Steeg, J., Veldkamp, A., and Willemen, L.: From land cover change to land function dynamics: a major challenge to improve land characterization, Journal of environmental management, 90, 1327-1335, 2009.

Virnodkar, S. S., Pachghare, V. K., Patil, V., and Jha, S. K.: CaneSat dataset to leverage convolutional neural networks for sugarcane classification from Sentinel-2, Journal of King Saud University-Computer and Information Sciences, 2020.

Xiong, J., Thenkabail, P. S., Gumma, M. K., Teluguntla, P., Poehnelt, J., Congalton, R. G., Yadav, K., and Thau, D.: Automated cropland mapping of continental Africa using Google Earth Engine cloud computing, ISPRS Journal of Photogrammetry and Remote Sensing, 126, 225-244, 2017.

Xu, P., Herold, M., Tsendbazar, N.-E., and Clevers, J. G.: Towards a comprehensive and consistent global aquatic land cover characterization framework addressing multiple user needs, Remote Sensing of Environment, 250, 112 034, 2020.

425 Yirsaw, E., Wu, W., Shi, X., Temesgen, H., and Bekele, B.: Land use/land cover change modeling and the prediction of subsequent changes in ecosystem service values in a coastal area of China, the Su-Xi-Chang Region, Sustainability, 9, 1204, 2017. 
https://doi.org/10.5194/essd-2021-253

Preprint. Discussion started: 12 October 2021

(c) Author(s) 2021. CC BY 4.0 License.

(c) (1)

Zhang, C., Pan, X., Li, H., Gardiner, A., Sargent, I., Hare, J., and Atkinson, P. M.: A hybrid MLP-CNN classifier for very fine resolution remotely sensed image classification, ISPRS Journal of Photogrammetry and Remote Sensing, 140, 133-144, 2018a.

Zhang, C., Ye, Y., Fang, X., Li, H., and Wei, X.: Synergistic Modern Global 1 Km Cropland Dataset Derived from Multi-Sets of Land Cover Products, Remote Sensing, 11, 2250, 2019.

Zhang, Q., Yuan, Q., Zeng, C., Li, X., and Wei, Y.: Missing data reconstruction in remote sensing image with a unified spatial-temporalspectral deep convolutional neural network, IEEE Transactions on Geoscience and Remote Sensing, 56, 4274-4288, 2018b.

Zhao, W. and Du, S.: Learning multiscale and deep representations for classifying remotely sensed imagery, ISPRS Journal of Photogrammetry and Remote Sensing, 113, 155-165, 2016.

435 Zhao, W., Guo, Z., Yue, J., Zhang, X., and Luo, L.: On combining multiscale deep learning features for the classification of hyperspectral remote sensing imagery, International Journal of Remote Sensing, 36, 3368-3379, 2015.

Zimmer-Gembeck, M. J. and Helfand, M.: Ten years of longitudinal research on US adolescent sexual behavior: Developmental correlates of sexual intercourse, and the importance of age, gender and ethnic background, Developmental review, 28, 153-224, 2008. 